\title{
Does Inter-Organellar Proteostasis Impact Yeast Quality and Performance During Beer Fermentation?
}

\author{
Bianca de Paula Telini, Marcelo Menoncin and Diego Bonatto* \\ Brewing Yeast Research Group, Centro de Biotecnologia da UFRGS, Departamento de Biologia Molecular e Biotecnologia, \\ Universidade Federal do Rio Grande do Sul, Porto Alegre, Rio Grande do Sul, Brazil
}

\section{OPEN ACCESS}

Edited by:

Francisco A. Cubillos,

Universidad de Santiago de Chile,

Chile

Reviewed by:

Brian Gibson,

VTT Technical Research Centre of

Finland Ltd, Finland

David Peris Navarro,

University of Oslo, Norway

*Correspondence:

Diego Bonatto

diegobonatto@gmail.com

Specialty section:

This article was submitted to

Evolutionary and Genomic

Microbiology,

a section of the journal

Frontiers in Genetics

Received: 11 October 2019

Accepted: 06 January 2020

Published: 31 January 2020

Citation:

Telini BdP, Menoncin M and Bonatto D

(2020) Does Inter-Organellar

Proteostasis Impact Yeast Quality and

Performance During Beer

Fermentation?

Front. Genet. 11:2.

doi: 10.3389/fgene.2020.00002
During beer production, yeast generate ethanol that is exported to the extracellular environment where it accumulates. Depending on the initial carbohydrate concentration in the wort, the amount of yeast biomass inoculated, the fermentation temperature, and the yeast attenuation capacity, a high concentration of ethanol can be achieved in beer. The increase in ethanol concentration as a consequence of the fermentation of high gravity $(\mathrm{HG})$ or very high gravity $(\mathrm{VHG})$ worts promotes deleterious pleiotropic effects on the yeast cells. Moderate concentrations of ethanol $(5 \% \mathrm{v} / \mathrm{v})$ change the enzymatic kinetics of proteins and affect biological processes, such as the cell cycle and metabolism, impacting the reuse of yeast for subsequent fermentation. However, high concentrations of ethanol (> 5\% v/v) dramatically alter protein structure, leading to unfolded proteins as well as amorphous protein aggregates. It is noteworthy that the effects of elevated ethanol concentrations generated during beer fermentation resemble those of heat shock stress, with similar responses observed in both situations, such as the activation of proteostasis and protein quality control mechanisms in different cell compartments, including endoplasmic reticulum (ER), mitochondria, and cytosol. Despite the extensive published molecular and biochemical data regarding the roles of proteostasis in different organelles of yeast cells, little is known about how this mechanism impacts beer fermentation and how different proteostasis mechanisms found in ER, mitochondria, and cytosol communicate with each other during ethanol/fermentative stress. Supporting this integrative view, transcriptome data analysis was applied using publicly available information for a lager yeast strain grown under beer production conditions. The transcriptome data indicated upregulation of genes that encode chaperones, cochaperones, unfolded protein response elements in ER and mitochondria, ubiquitin ligases, proteasome components, $\mathrm{N}$-glycosylation quality control pathway proteins, and components of processing bodies (p-bodies) and stress granules (SGs) during lager beer fermentation. Thus, the main purpose of this hypothesis and theory manuscript is to provide a concise picture of how inter-organellar proteostasis mechanisms are connected 
with one another and with biological processes that may modulate the viability and/or vitality of yeast populations during HG/NHG beer fermentation and serial repitching.

Keywords: proteostasis, brewing yeasts, ethanol stress, beer fermentation, inter-organellar communication, transcriptome

\section{INTRODUCTION}

During beer production, ethanol generated as a by-product of fermentation is exported to the extracellular environment, where it accumulates. Depending on the initial mono-, di-, and trisaccharide concentrations present in the wort, the amount of yeast cell biomass inoculated, fermentation temperature, and the attenuative capability of yeast strains employed by the brewer, a high concentration of ethanol can be achieved in beer (Puligundla et al., 2011).

At present, the brewing industry is trying to implement the use of very high gravity (VHG) worts $\left(24^{\circ} \mathrm{P}\right.$ or approximately $1.101 \mathrm{~kg} \cdot \mathrm{L}^{-1}$ dissolved solids) to produce beer, which can save energy, time, labor, and capital costs, and improve plant efficiency (Silva et al., 2008; Puligundla et al., 2011). Beer produced from VHG worts contains high quantities of ethanol and other volatiles, which are dissolved in oxygen-free water to produce regular beers with $5 \%(\mathrm{v} / \mathrm{v})$ ethanol (Stewart, 2010). However, the use of VHG worts imposes challenges for serial repitching due to the osmotic and oxidative stresses that yeast cells experience in the first hours of fermentation, which are followed by ethanol, nutritional, and thermal (cold shock) stresses in the later phases of fermentation and the beginning of cold maturation (Gibson et al., 2007). These stress conditions can lead to yeast slurries that display sluggish fermentation and poor viability, which precludes their use in subsequent fermentations (Huuskonen et al., 2010).

The increase in ethanol concentrations, as a consequence of VHG wort fermentation, can have pleiotropic effects in yeast. Ethanol is a chaotropic substance that affects cell macromolecular structures by reducing hydration (Hallsworth, 1998; Cray et al., 2015). Moderate concentrations of ethanol (around $5 \% \mathrm{v} / \mathrm{v}$ ) can alter the enzymatic kinetics of proteins associated with primary metabolism (e.g. glycolysis), and affect different biological processes, such as the cell cycle (Hallsworth, 1998). In comparison, high concentrations of ethanol (> 5\% v/v) can cause substantial changes in the structure and composition of hydrophobic molecules within the cell (Hallsworth, 1998). Thus, by reducing the water activity in the cell, ethanol promotes a water stress condition (Hallsworth, 1998). In a general sense, the effects of high concentrations of ethanol resemble those observed during heat shock conditions (defined as exposure to temperatures $>35^{\circ} \mathrm{C}$ ), and similar responses are observed in response to both stress situations, such as changes in membrane composition and synthesis of small protective osmolytes (e.g. glycerol and trehalose) (Piper, 1995). Interestingly, it was recently demonstrated by transcriptome analysis using RNA-seq data that ethanol tolerance in different Saccharomyces cerevisiae strains also depends on a series of environmental conditions (e.g. the presence or absence of dissolved oxygen), pointing to a strain-by-oxygen-by-alcohol interactions that lead to ethanol tolerance (Sardi et al., 2018).

Protein folding and activity, key features of "proteostasis", are strongly affected by ethanol. In this review, proteostasis mechanisms are defined as all steps required for a protein to exert its function(s), from protein biogenesis to degradation, including all post-translational changes that the protein experiences in between.

In mammalian models, it has been shown that posttranslational modifications of proteins, like mannosylation and galactosylation, are substantially changed in ER and Golgi after ethanol shock (Ghosh et al., 1995; Esteban-Pretel et al., 2011). In yeast, there is limited available data on how ethanol affects posttranslational modification of proteins, but it is clear that protein structure and activity change in the presence of ethanol (Hallsworth, 1998). It has been observed that ethanol can induce heat shock proteins like Hsp104p, Hsp70p, and Hsp26p, and oxidative stress-response proteins, like Ctt1p, Sod1, and Sod2p under moderate concentrations of ethanol (6\% v/v) (Stanley et al., 2010). DNA microarray data supports the idea of a fermentative stress response associated with ethanol toxicity in industrial lager fermentations (Gibson et al., 2007).

Despite the paucity of data regarding the effects of ethanol toxicity in the modulation of yeast proteostasis mechanisms during VHG beer fermentation and serial repitching by using publicly available DNA microarray data (Table S1 and Figure S1), we observed the upregulation of genes linked to lager beer fermentation (Figures S2A, B), including differentially expressed genes (DEGs) associated to organellar proteostasis mechanisms in DNA microarray single analysis (Figures S3A, B and S4A, B) and DNA microarray meta-analysis (Figures S5A, B and S6A, B). The Pan-DEGs resulting from both DNA microarray analyses (Figures S1 and S9A, B) include genes linked to ERassociated unfolded protein response (UPR), endoplasmic reticulum-associated protein degradation (ERAD) responses (Figures 1A, B), and mitochondria-associated proteostasis (Figures 2A, B), suggesting cellular cross-talk among organellar proteostasis mechanisms. It is important to note that all three gene expression datasets (GSEs) analyzed in this work (Table S1) employed the Affymetrix Yeast Genome 2.0 Array for transcript detection of both $S$. cerevisiae and Schizosaccharomyces pombe yeast species (https://www.ncbi. nlm.nih.gov/geo/query/acc.cgi?acc = GPL2529), which can potentially introduce a bias when transcripts of Saccharomyces pastorianus are evaluated due to the hybrid genome of this species (Okuno et al., 2016). In order to evaluate if the parental genomes of $S$. pastorianus display some specific expression pattern, Horinouchi et al. (2010) designated a 

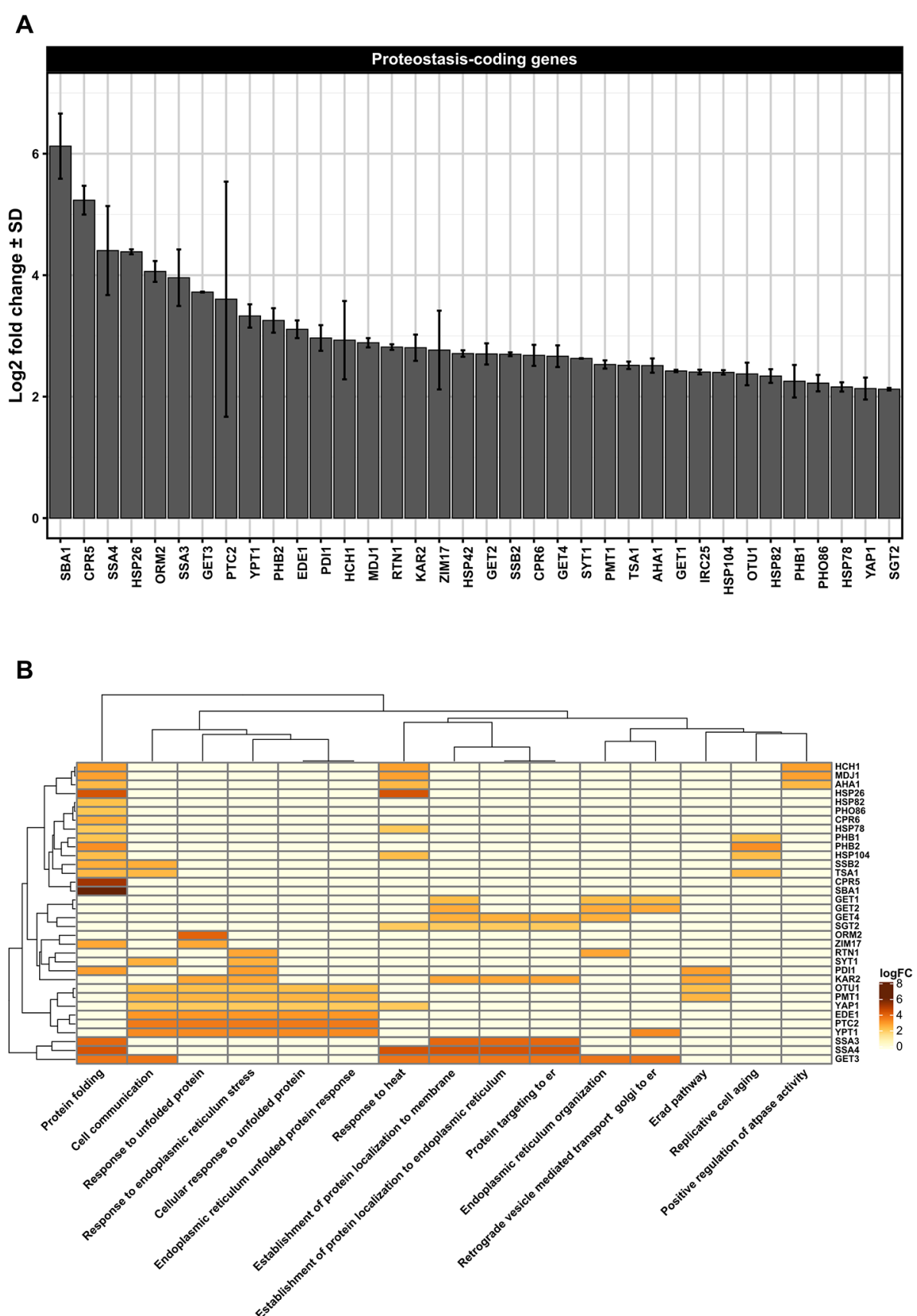

FIGURE 1 | (A) Differentially upregulated Pan-genes associated with proteostasis observed in the lager yeast CB11 strain during beer fermentation. The mean expression values are indicated by log2 fold change \pm standard deviation (SD) on the $y$-axis and in the inset. Gene names are indicated on the $x$-axis. (B) Heatmap plot showing the clustered differentially upregulated genes associated with proteostasis observed in CB11 during beer fermentation and the associated clustered biological processes from gene ontology analysis (Figure S1). Heatmap rows and columns were grouped using the Euclidean distance method and complete linkage.

custom DNA microarray platform for S. pastorianus transcriptome analysis containing probes for both $S$. cerevisiae and Saccharomyces bayanus genomes. This custom DNA microarray was employed to evaluate gene expression pattern in the lager brewing strain Weihenstephan 34/7 during a pilot- scale fermentation condition. The transcriptome data gathered by the authors indicated a strong correlation between the expression levels of $S$. cerevisiae and S. bayanus orthologous genes during fermentation, allowing discriminate only a small set of S. cerevisiae or S. bayanus DEGs (Horinouchi et al., 2010). On 


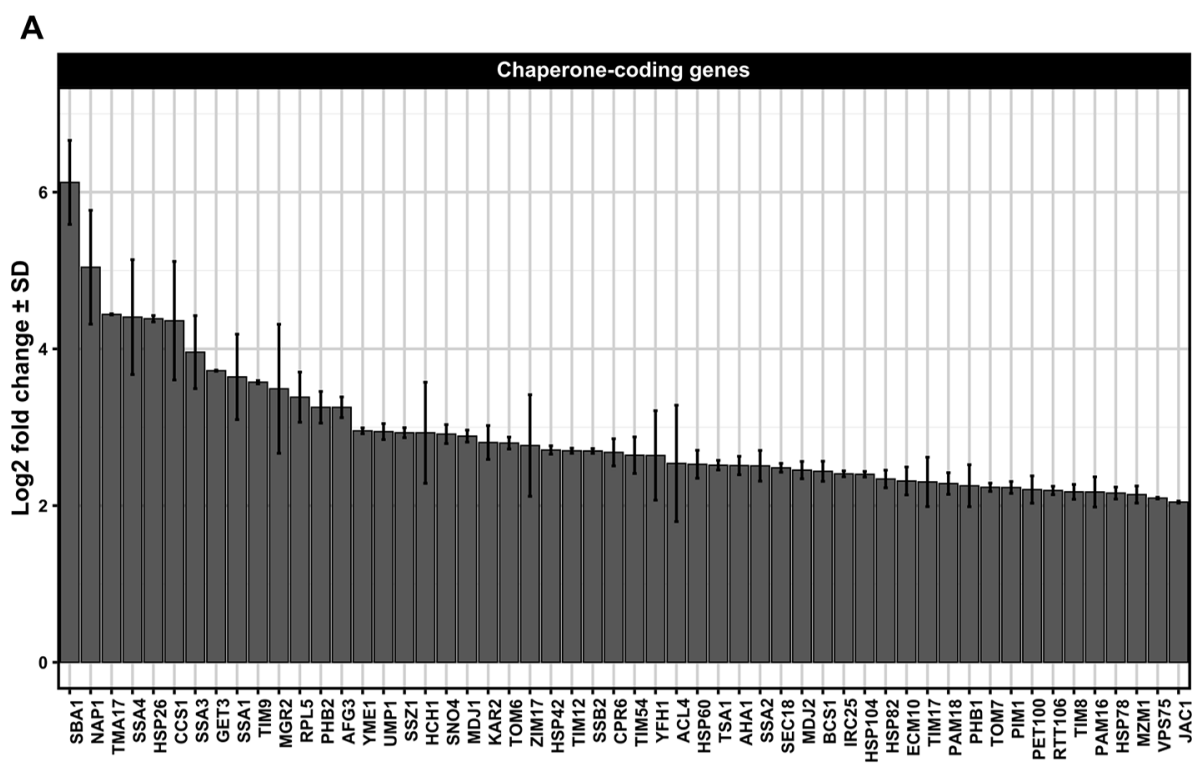

B

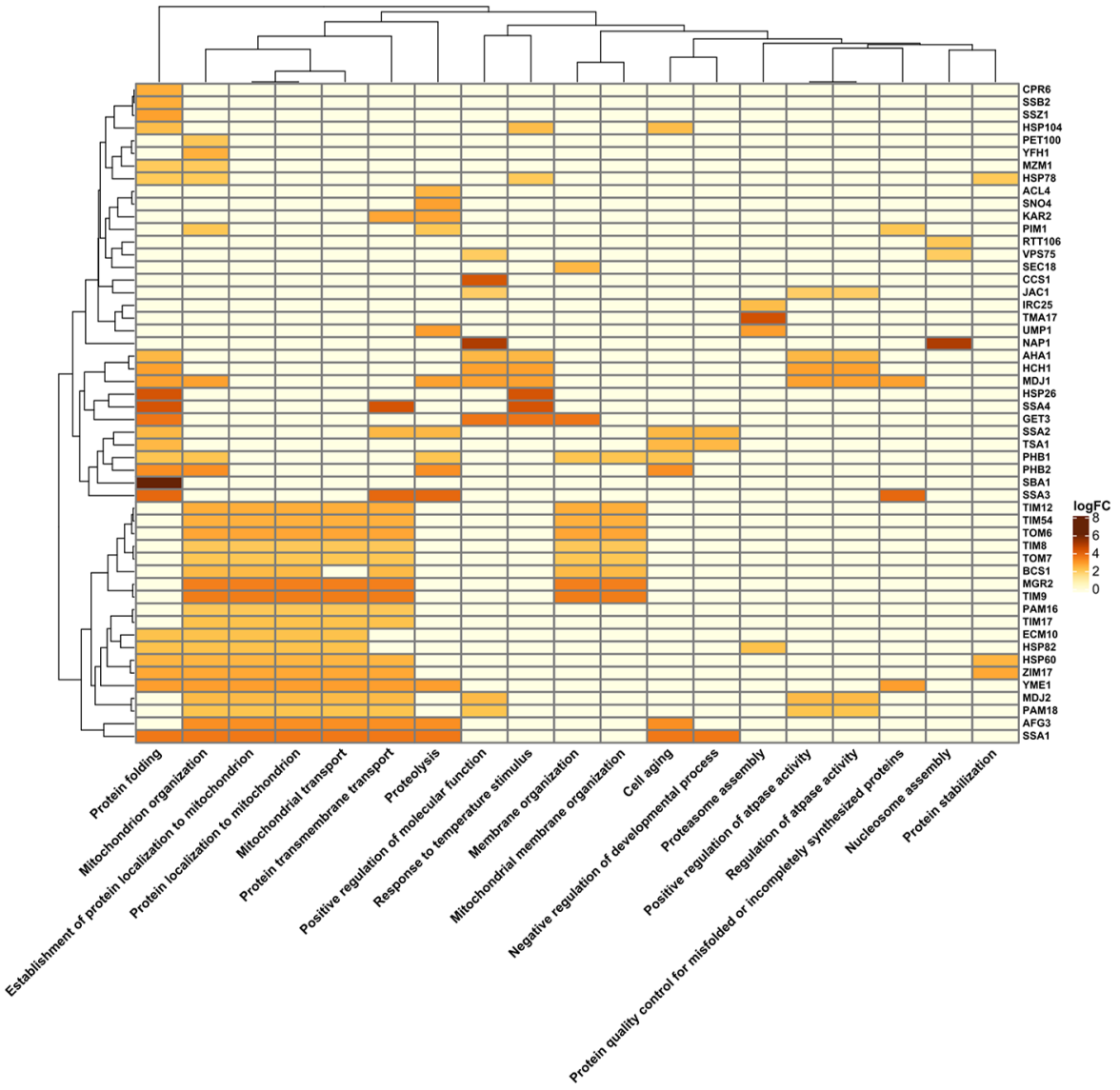

FIGURE 2 | (A) Differentially upregulated Pan-genes associated with chaperones and folding proteins observed in the lager yeast CB11 strain during beer fermentation. The mean expression values are indicated by log2 fold change \pm standard deviation (SD) on the $y$-axis and in the inset. Gene names are indicated on the $\mathrm{x}$-axis. (B) Heatmap plot showing the clustered differentially upregulated genes associated with chaperones and folding proteins observed in CB11 during beer fermentation and the associated clustered biological processes from gene ontology analysis (Figure S1). Heatmap rows and columns were grouped using the Euclidean distance method and complete linkage. 
the other hand, the use of RNA sequencing technologies for evaluation of gene expression in S. pastorianus strains during beer production is virtually absent, making it difficult to understand the contribution of parental genomes of $S$. pastorianus in ethanol tolerance and proteostasis. Thus, considering the importance of $S$. pastorianus for brewing industry in general and for hybrid yeast species research (Gorter de Vries et al., 2019a; Gorter de Vries et al., 2019b), it is imperative to design new experimental procedures for the analysis of the influence of hybrid genomes in proteostasis and ethanol tolerance.

\section{YEAST ER PROTEOSTASIS AND ETHANOL TOLERANCE}

The endoplasmic reticulum (ER) consists of an extensive network of membranes that originates at the nuclear envelope and flows through the cytoplasm (English and Voeltz, 2013). It is the site of secretory, membrane, lysosomal, and vacuolar protein synthesis. Besides proteins, the ER is also fundamental for the synthesis of lipids and the assembly of lipid bilayers (van Meer et al., 2008). In the ER, proteins are structurally modified, which involves cleavage of signal sequences, $N$-linked glycosylation, disulfide bond formation, folding of monomers, and oligomerization (Braakman and Hebert, 2013). Correct protein folding is facilitated by different molecular chaperones and folding enzymes present in the ER, such as protein disulfide isomerases (PDIs). When a protein is unable to fold correctly, an ER quality control (ERQC) system is activated, comprised of both UPR and ERAD mechanisms (Brodsky and Wojcikiewicz, 2009).

Considering that many proteins found in the ER contain $\mathrm{N}$ linked glycans, it is logical to consider that proteostasis mechanisms are largely associated with $N$-glycan synthesis in the ER. In fact, $N$-glycan modification by different glycanases found in ER defines the final destination of polypeptides, and the trimming of glucose residues recruit lectin chaperones that facilitate protein folding (Molinari, 2007; Ferris et al., 2014). Until now, data regarding $N$-glycan processing in yeast during VHG beer fermentation or yeast reuse has been extremely limited. However, our transcriptome data single- and metaanalysis (Figure S1) of the proprietary lager yeast CB11 strain (Coors Brewing Limited (Burton on Trent, UK) (Lawrence et al., 2012) under fermentation conditions, when compared to propagation conditions, point to upregulation of genes related to $N$-glycan processing, like PDI1 and PMT1, which are also important components of the ERAD response (Figures 1A, B). ERAD components export unfolded proteins to the cytosol, which are ubiquitinated and degraded by the $26 \mathrm{~S}$ proteasome (Brodsky and Wojcikiewicz, 2009; Hetz et al., 2015). The recognition step of unfolded protein can occur either on the luminal side (ERAD-L), the cytosolic side (ERAD-C), or inside of the ER membrane (ERAD-M) (Thibault and Ng, 2012). Protein disulfide isomerase 1, or Pdilp, is essential for cell viability and is highly abundant in the ER (Mizunaga et al., 1990; Pfeiffer et al., 2016). Pdilp is also involved in the removal of aberrant disulfide bridges (Gilbert, 1997; Pfeiffer et al., 2016). Interestingly, Pdi1p has chaperone activity, even with proteins that do not form disulfide bridges (Pfeiffer et al., 2016), assisting in the unfolding and the export of ERAD-client proteins from the ER (Weissman and Kimt, 1993). Finally, Pmt1p is an O-mannosyltransferase that, together with Pmt2p, exerts proteostasis control of ER proteins. Pmtlp interacts with Pdilp in order to promote the correct folding of ER-resident proteins or to target misfolded proteins to Hrd1p, a major ERAD-associated E3 ubiquitinprotein ligase (Goder and Melero, 2011). It is worth noting that Pdilp interacts with Htm1p/Mnllp, an alpha-1,2-specific exomannosidase that generates Man7GlcNac2, an oligosaccharide structure on glycoproteins target for ERAD (Clerc et al., 2009). Moreover, Htmlp/Mnllp is required for Yos9p activity (Clerc et al., 2009), a $75 \mathrm{kDa}$ soluble ER glycoprotein (Friedmann et al., 2002) that has been shown to have an important role in glycoprotein degradation (Szathmary et al., 2005). It should be point that YOS9 gene was found overexpressed in DNA microarray single analysis only (Figures S4A, B). The roles of Htm1p/Mnllp in yeast cells subjected to VHG beer fermentation and/or ethanol stress are poorly understood, but it has been demonstrated that ethanol can impair the biosynthesis of $\mathrm{N}$ glycans in liver cell models in vitro (Welti and Hülsmeier, 2014). This indicates that $N$-glycan biosynthesis and processing may be negatively affected by ethanol/fermentation stress during VHG or even high gravity (HG) beer production.

In addition to $N$-glycan structural alterations promoted by ethanol, the presence of unfolded proteins in ER reduces or even stops the translation of new proteins, and also exposes sticky hydrophobic amino acids in unfolded proteins, promoting socalled proteotoxicity (Ron, 2002; Mori, 2015), which is sensed by the transmembrane protein Ire1. Ire1p undergoes oligomerization and autophosphorylation and activates the endoribonuclease domain on the cytosolic side of the membrane that removes a regulatory intron in the HAC1 mRNA (Chapman and Walter, 1997; Sidrauski and Walter, 1997), leading to the translation of active Haclp, a bZip transcription factor associated with ER proteostasis (Liu and Chang, 2008). Noteworthy, Navarro-Tapia et al. (2017) showed that low to high concentrations of ethanol ( $\leq$ $8 \% \mathrm{v} / \mathrm{v}$ ) did not promote protein unfolding in yeast cells, but did trigger UPR through an unknown mechanism in laboratory yeast strains cultured in synthetic medium. However, Miyagawa et al. (2014) showed that an increase in ethanol concentration, from 8 to $16 \%(\mathrm{v} / \mathrm{v})$ in a synthetic culture medium, promoted the constant expression of HAC1 spliced form mRNA, which demonstrated that UPR can become chronically activated. In addition, the same authors verified that Kar2p associated with unfolded protein aggregates in the ER when yeast cells were challenged with ethanol at a concentration of $16 \%(\mathrm{v} / \mathrm{v})$, supporting the idea that very high concentrations of ethanol potentially induce protein aggregates in the ER and trigger ERQC (Miyagawa et al., 2014).

Our transcriptome data indicated that Pan-DEGs related to the classical UPR pathway, like KAR2, PTC2, and YPT1, are upregulated in lager beer fermentation compared to the yeast propagation step (Figures 1A, B). Ptc2p is a type $2 \mathrm{C}$ serine/ threonine phosphatase that downregulates the UPR mechanism 
by dephosphorylating Ire2p (Welihinda et al., 1998), while Ypt1p is a yeast Rabl homolog that interacts with unspliced $H A C 1$ mRNA and regulates the UPR by promoting the decay of HAC1 mRNA (Tsvetanova et al., 2012). Yptlp has been linked to the maintenance of Golgi morphology and protein composition, participates in ER to Golgi anterograde/retrograde transport, and is necessary for intra Golgi transport (Kamena et al., 2008). While anterograde/retrograde ER to Golgi responses have been extensively studied in yeast and other model organisms, and the functions of a number of different protein complexes involved in these processes have been discerned (Lee et al., 2004), the influence of anterograde/retrograde ER to Golgi transport in brewing yeast vitality or beer fermentation is unknown. However, we hypothesize that this mechanism may be negatively modulated by high ethanol concentrations during VHG beer fermentation or yeast reuse. In support of this idea, it was previously shown that the rat PC12 cell line, when subjected in vitro to a low alcohol concentration $(30 \mathrm{mM})$, exhibited delayed anterograde ER to Golgi transport, fragmented Golgi morphology, and a decreased number of secretory vesicles (Tomás et al., 2012). Interestingly, 5\% of all eukaryotic proteins (referred to as tailanchored (TA) proteins) possess a unique carboxy-terminal transmembrane region that targets them to the ER membrane (Stefanovic and Hegde, 2007). Considering that these proteins contain a hydrophobic domain that makes them prone to aggregation in the aqueous environment of the ER lumen, they should be targeted to the ER membrane to avoid the formation of protein aggregates. Thus, in order to guide the entry of TA proteins into the ER membrane, the guided entry of TA proteins (GET) pathway mediates the process, also acting in vesicle fusion and retrograde Golgi to ER responses (Denic et al., 2013). Moreover, the GET pathway is necessary for the retrieval of the Erd2p HDEL receptor from the Golgi to the ER (Schuldiner et al., 2005). Erd2p is an important component that retain proteins bearing a C-terminal tetrapeptide HDEL sequence in the ER, like the ER chaperone Kar2p (Semenza et al., 1990), invertase, and many other secreted proteins. In our transcriptome data analysis, we found that during lager beer fermentation, the Pan-DEGs GET1, GET2, GET3, GET4, and SGT2 are significantly upregulated (Figures 1A, B). GET proteins are core components of GET pathway that promote the transfer of TA proteins from ribosomes to the Get $4 \mathrm{p} / \mathrm{Get} 5 \mathrm{p} / \mathrm{Sgt} 2 \mathrm{p}$ complex and to the chaperone Get3p (Chartron et al., 2012). Then, Get1p and Get2p, which comprise a transmembrane complex, drive a conformational change that enables the release of TA proteins from Get3p and, as a consequence, insertion into the ER membrane (Wang et al., 2014). In the context of beer fermentation and ethanol stress, we speculate that ethanol generated during fermentation induces conformational changes in $\mathrm{N}$-glycans and secreted proteins that potentially leads to the formation of aggregates in the ER, followed by modification of the structure and function of Golgi. This may result in the activation of ERQC mechanisms and promote the retrograde response of Golgi to ER by stimulating the function of the GET pathway (Figure 4). Finally, the induction of ERQC due to ethanol generated during beer fermentation may also occur in cytoplasm and mitochondria, especially due to the activity of multi-organellar ubiquitin ligases and chaperones.

\section{CYTOSOL PROTEOSTASIS IN BREWING YEAST AND THE IMPACT ON BEER FERMENTATION}

In the cytosol, misfolded proteins that have exposed hydrophobic amino acid residues are recognized by protein quality control mechanisms (Buchberger et al., 2010). The cytoplasmic proteostasis mechanism in yeast comprises the heat shock response (HSR) (Mager and Ferreira, 1993), which promotes the expression of molecular chaperones and the proteasome system (Parsell et al., 1993). Similar to UPR, the HSR is induced by different stress conditions that lead to proteotoxicity. In S. cerevisiae, the HSR is regulated by the heat shock factor 1 (Hsflp) transcription factor, encoded by the HSF1 gene (Weindling and Bar-Nun, 2015). Hsflp promotes an adaptive response to different stressor agents, including ethanol (Weindling and Bar-Nun, 2015). Yeast cells treated with 6\% (v/v) ethanol show induction of Hsflp activity (Lee et al., 2000), while Hsflp mutants were defective in ethanol stress-induced target gene expression (Takemori et al., 2006). Interestingly, the ER oxidoreductin, which is encoded by ERO1 and induces protein disulfide bonds, was upregulated by Hsflp in yeast cells exposed to ethanol (Takemori et al., 2006), pointing to a crosstalk between HSR and ERQC mechanisms. Unfortunately, the activity of HSR and ERQC in conditions of VHG beer fermentation or yeast serial repitching is not well understood, but we speculate that modulation of the crosstalk between HSR and ERQC mechanisms may promote ethanol tolerance and cell adaptability during beer fermentation. In line with this hypothesis, ubiquitin ligases, which function by transferring ubiquitin to misfolded/unfolded proteins thus targeting them to the $26 \mathrm{~S}$ proteasome complex, are key components that regulate both HSR and ERQC (Szoradi et al., 2018). It is well known that different organelles have their own specific ubiquitin ligases, such as Hrd1p and Doa10p in the ER (Ruggiano et al., 2014), Sanlp in the nucleus (Gardner et al., 2005), and Ubrlp, Ubr2p, Hul5p, and Rsp5p in the cytosol (Prasad et al., 2018). However, different ubiquitin ligases have overlapping functions, such as Doa10p in nucleus and cytosol, San1p in cytoplasm, and Ubr1p in the ER (Szoradi et al., 2018). This ubiquitin ligase network is an essential component of inter-organellar proteostasis, yet very little is known about how this communication is mediated. For example, the overexpression of cytosolic Rsp5p, a NEDD4 family E3 ubiquitin ligase, improve thermoresistance and stress tolerance in yeast strains used for bioethanol production (Hiraishi et al., 2006; Shahsavarani et al., 2012). Disruption of RSP5 increase the production of isoamyl alcohol and isoamyl acetate in laboratory yeast strains (Abe and Horikoshi, 2005). Rsp5p is part of the so-called "Rsp5-ART ubiquitin ligase adaptor network", which acts to promote the endocytosis and degradation of misfolded integral membrane proteins found in the ER, Golgi, and plasma membrane (Zhao et al., 2013). Additionally, Rsp5p 
interacts with another important cytosolic E3 ubiquitin ligase named Ubrlp, which is a component of the stress-induced homeostatically-regulated protein degradation (SHRED) pathway (Szoradi et al., 2018).

The SHRED pathway is initially activated by transcription of the hydrophilin-coding gene ROQ1 by different stress conditions due to the presence of Msn2p/4p and Hsflp-associated stress response elements in the ROQ1 promoter (Yamamoto et al., 2005; Verghese et al., 2012; Szoradi et al., 2018). Once translated, Roq1p is cleaved by the endopeptidase Ynm3p, and cleaved Roqlp binds to Ubrlp changing its substrate specificity and promoting the degradation of misfolded proteins at the ER membrane and in the cytosol by the proteasome (Szoradi et al., 2018). Ubrlp interacts with the chaperone Hsp70p and with Sse1p, the ATPase component of the heat shock protein Hsp90 chaperone complex (Nillegoda et al., 2010). Moreover, it has been demonstrated that Ubrlp is a fundamental component of ERAD when yeast cells are exposed to heat or ethanol stress, bypassing the functions of the canonical Hrd1p/Der3p and Doa10p (Stolz et al., 2013). Thus, considering the importance of Rsp5p and Ubrlp in heat and ethanol stress response, we hypothesize that under conditions of VHG/HG beer fermentation, the Rsp5-ART ubiquitin ligase adaptor network and SHRED pathway actively target protein aggregates present in the ER and cytosol to ERAD (Figure 4).

Besides ubiquitin ligases, many chaperones are essential to repair and/or prevent misfolded proteins even before they can be targeted to ERAD. In yeast, chaperones are classified in eight distinct families, which are the small heat-shock proteins (SMALL), the AAA+ family, the CCT/TRiC complex, the
prefoldin/GimC (PFD) complex, Hsp40, Hsp60, Hsp70, and Hsp90 families (Gong et al., 2009). From transcriptome data analysis, we observed the upregulation of 54 Pan-DEGs linked to chaperone activity (Figures 2A, B) in the lager yeast strain during beer fermentationas compared to the propagation step. Of these 54 Pan-DEGs linked to chaperone activity, 21 PanDEGs encode for chaperone proteins that are found in the cytoplasm and mitochondria (Figure 3A) and belong to the HSP70, HSP40, SMALL, AAA+, HSP60, and HSP90 families (Figure 3B).

Considering the chaperones found in cytoplasm that belong to the Hsp70 family, we found that the Pan-DEGs SSA1-4, SSZ1, and SSB2 were upregulated during beer fermentation in comparison to propagation (Figures $2 \mathbf{A}, \mathbf{B}$ ). The roles of Hsp70s proteins in yeast subjected to ethanol stress are extensively documented, including in beer production. For example, it was reported that FES1, SSA2, SSA3, SSA4, and SSE1 are upregulated in a synthetic wort that mimicked a VHG beer fermentation (Qing et al., 2012). Other studies based on proteomics and quantitative RT-qPCR also confirmed the expression of cytosolic Hsp70p during the early phases of beer fermentation in different lager strains (Brejning et al., 2005; Smart, 2007), and it was clearly demonstrated that moderate concentrations of ethanol $(>4 \% \mathrm{v} / \mathrm{v})$ induce the expression of Hsp70 proteins (Piper et al., 1994). In fact, proteins of the Hsp70 family display important functions not only as chaperones, but also in targeting misfolded proteins for proteasome degradation (Kettern et al., 2010; Kim et al., 2013). In addition, Hsp70 proteins form a bi-chaperone system with Hsp104p, a heat shock protein belonging to the AAA+ family
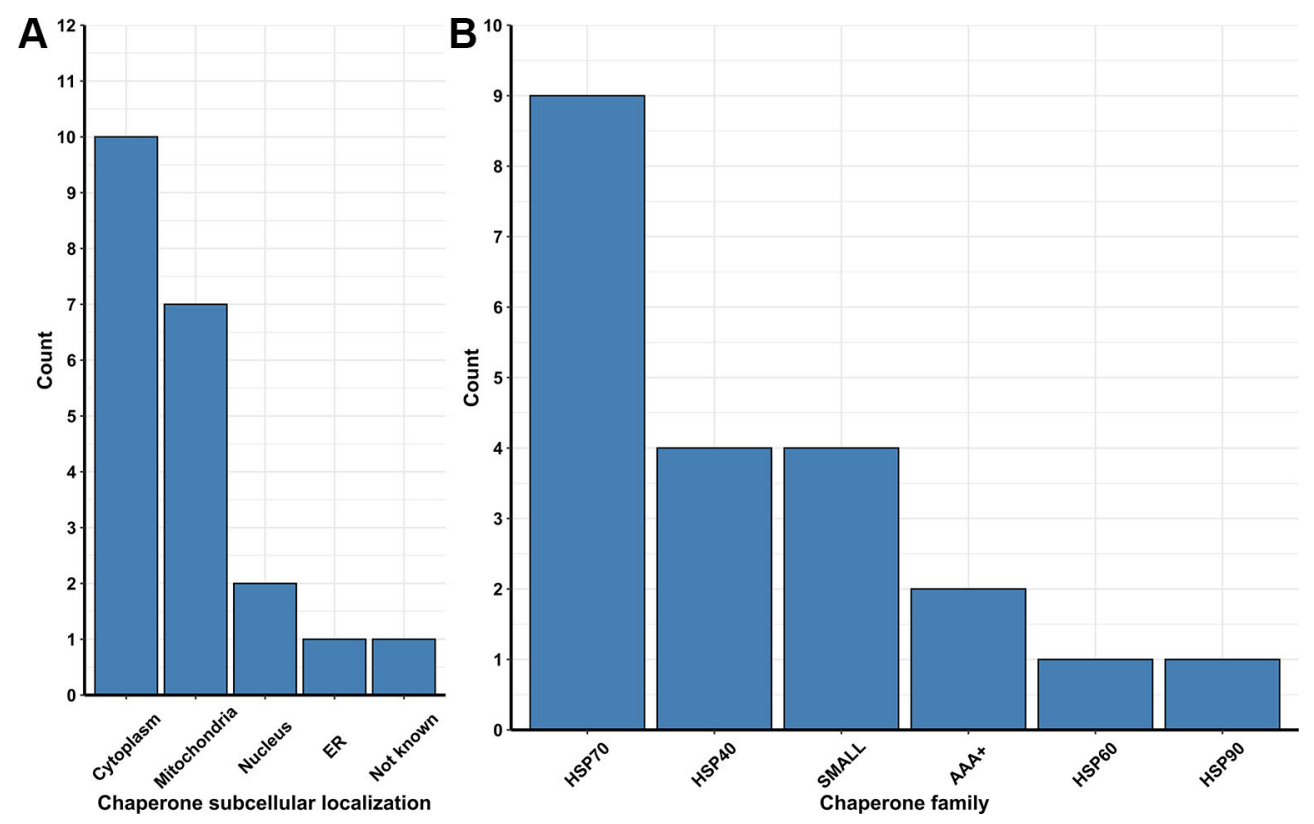

FIGURE 3 | (A) Number of chaperones and folding protein coding Pan-genes found to be upregulated in different organelles of the lager yeast CB11 strain during beer fermentation, in comparison to yeast propagation. (B) Number of coding Pan-genes upregulated in CB11 during beer fermentation, in comparison to yeast propagation, that are linked to the major chaperone protein families. 
(Zolkiewski et al., 2012), and promote the disaggregation and resolubilization of misfolded proteins (Weibezahn et al., 2005). The transcriptome data also indicated that HSP104 is upregulated during beer fermentation compared to propagation (Figures 2A, B), supporting our hypothesis that ethanol may promote the formation of misfolded protein aggregates in lager yeast strains during beer fermentation, which likely triggers the activity of Hsp70p and Hsp104p to refold and resolubilize the protein aggregates or target them to the proteasome.

Corroborating the importance of HSP104 for VHG beer fermentation, Rautio et al. (2007) showed that HSP104 is induced in the first 10 to $30 \mathrm{~h}$ of fermentation together with TPS1, which encodes trehalose phosphate synthase, a key enzyme involved in trehalose biosynthesis and ethanol stress protection (Alexandre et al., 2001) during beer fermentation. The roles of trehalose as a molecular chaperone in protecting yeast cells against protein aggregation are well understood (Singer and Lindquist, 1998) and a synergistic effect of Hsp104p on trehalose accumulation and degradation has been observed (Iwahashi et al., 1998). However, trehalose and Hsp104p are both required when protein aggregation can be reversible in yeast cells (Sethi et al., 2018). It will be interesting to determine if Hsp104p and trehalose act synergistically in VHG beer protecting yeast cells in the early phases of the fermentation process.

In addition to Hsp70 and AAA+ families, we also observed two additional HSP members with high expression in the cytosol of lager yeast cell during beer fermentation compared to cell propagation, which were the SMALL and Hsp40 proteins (Figure 3B). The SMALL or small heat shock proteins $/ \alpha$ crystallin (sHSP) family is comprised of Hsp26p and Hsp42p in $S$. cerevisiae, two proteins important for preventing unfolded protein aggregation that have overlapping functions in nonstressed and stressed yeast cells (Haslbeck et al., 2004). It was previously demonstrated that $\mathrm{Hsp} 26 \mathrm{p}$ co-assembles with misfolded proteins and allows the Hsp104p/Hsp70p/Hsp40p complex to disaggregate them (Cashikar et al., 2005). Interestingly, HSP26 and other HSP-coding genes were found to be upregulated in yeast strains isolated from sherry wines (Aranda et al., 2002), as well as in lager yeast cells in $16^{\circ} \mathrm{P}$ and 24 ${ }^{\circ} \mathrm{P}$ wort after $24 \mathrm{~h}$ of fermentation (Odumeru et al., 1992). In addition, it was shown that Hsp26P is a key HSP for ethanol production (Sharma, 2001).

Another interesting target of our transcriptome analysis was the HSP82 Pan-DEG, which was found to be upregulated in lager yeast during beer fermentation (Figures 2A, B), corroborating the previous data of Gibson et al. (2008). Additionally, in brewing yeast, it has been demonstrated by proteomics and transcriptomics that ethanol stress induces the expression of Hsp82p in wine yeasts (Aranda et al., 2002; Navarro-Tapia et al., 2016) and bioethanol yeast strains (Li et al., 2010). The Hsp82 protein, which belongs to the HSP90 family, is an abundant and essential dimeric ATP-dependent chaperone (Borkovich et al., 1989; Richter et al., 2001). It is required to reactivate proteins damaged by heat without participating in de novo folding of most proteins (Nathan et al., 1997). Hsp82 target proteins include steroid hormone receptors and kinases (Mayr et al., 2000). It has been demonstrated that Hsp82p is regulated by several cochaperones, including Ahalp and Hchlp, both of which activate the ATPase function of Hsp82p (Panaretou et al., 2002) and whose Pan-DEGs were found upregulated in lager yeast during beer fermentation (Figures 2A, B). A third cochaperone named Cpr6p, a peptidyl-prolyl cis-trans isomerase (cyclophilin) that interacts with Hsp82p, and together with Cpr7p, is required for normal yeast growth (Zuehlke and Johnson, 2012). CPR6 was found to be upregulated in our transcriptome analysis during beer fermentation (Figures 2A, B), but little is known about its roles during beer fermentation. However, protein-protein interaction data (Figure S10) indicate that Cpr6p interacts with $\mathrm{Pbplp}$, a component of processing bodies (p-bodies) and stress granules (SGs), which may be induced by severe ethanol stress, heat shock, or glucose deprivation (Kato et al., 2011). Induction of p-bodies and SGs by UPR, which has been observed in mammalian cells (Harding et al., 2000; Anderson and Kedersha, 2008) may also occur in yeast cells. In fact, it would be interesting to determine whether p-bodies/SGs are formed during beer fermentation and if they are associated with proteostasis in cytosol and/or the ER. Cpr6p also interacts with $\mathrm{Rpd} 3 \mathrm{p}$ (Figure S10), a conserved histone deacetylase that together with $\operatorname{Sin} 3 p$ and Umelp comprise the Sin 3 complex, a global regulator of transcription that is linked to a series of physiological conditions in yeast and other organisms (Silverstein and Ekwall, 2005), such as ethanol stress (Ma and Liu, 2012). Thus, Cpr6p could be an important co-chaperone that together with Hsp82 may serve as a hub for p-bodies/SGs and epigenetic regulation of genes linked to beer fermentation and proteostasis.

\section{MITOCHONDRIAL PROTEOSTASIS IN BREWING YEAST}

During beer production, yeast mitochondria exert important functions despite the catabolic repression of nuclear genes encoding mitochondrial proteins linked to respiration (O'Connor-Cox et al., 1996). In fact, mitochondria are not only the primary site of lipid and ergosterol synthesis, but they also provide a series of metabolites originating from central carbon and proline-arginine metabolism (Kitagaki and Takagi, 2014). A large proportion of cellular radical molecules are produced as a result of mitochondrial metabolism, which can strongly affect yeast physiology (Kitagaki and Takagi, 2014). Despite the metabolic and physiological importance of mitochondria, mutations linked to the mitochondrial genome that result in petite phenotypes can result in the production of off-flavors (related to synthesis of esters and fusel alcohols) in beer fermentation (Ernandes et al., 1993). Finally, in lager yeasts and possibly in ale strains, mitotype can have a strong influence on temperature tolerance (Baker et al., 2019).

Proteostasis in mitochondria includes different chaperones and proteases, as well as proteins that participate in interorganellar communication, where defects in mitochondrial proteostasis impacts health and aging (Moehle et al., 2019). 
Similar to ER, mitochondria have a so-called "mitochondrial unfolded protein response" or mtUPR, which was initially characterized in mammalian cells (Zhao, 2002).

Considering that mitochondria have distinct subcompartments within the organelle (e.g. matrix, outer membrane, and intermembrane space), protein import and sorting processes are very complex (Neupert and Herrmann, 2007). Most mitochondrial proteins are imported as unfolded precursors by means of the translocase of outer membrane (TOM) and translocase of inner membrane (TIM) complexes. Upon translocation into the mitochondria, the proteins undergo chaperone-assisted folding (Neupert and Herrmann, 2007).

The transcriptome analysis of lager yeast cells during beer fermentation revealed that TIM-related Pan-DEGs including TIM8, TIM9, TIM12, TIM17, and TIM54 are upregulated (Figures 2A, B). Tim8p and Tim9p belong to the mitochondrial intermembrane space protein transporter complex, which together with Tim10p, Tim12p, and Tim13p, mediates the transit of proteins destined for the inner membrane across the mitochondria intermembrane space (Davis et al., 2007). Tim9p/ Tim10p and Tim9p/Tim10p/Tim12p interact with Tim22p, comprising a multioligomeric complex with Tim54p, Tim $22 \mathrm{p}$, Tim18p, and Sdh3p (Gebert et al., 2011). The Tim22 complex mediates the insertion of large hydrophobic proteins, like carrier proteins with multiple transmembrane segments, as well as Tim23p, Tim17p, and Tim22p into the inner membrane (Mokranjac and Neupert, 2009). Tim17p is a component of the Tim23 complex, which promotes the translocation and insertion of proteins into the inner mitochondrial membrane (Mokranjac and Neupert, 2009). The Tim23 complex is composed of a membrane-embedded part, which forms the import motor. This component is formed by Tim14p (Pam18p), Tim16 (Pam16p), Tim44p, Mgelp, and mitochondrial Hsp70p (Mokranjac and Neupert, 2009). The Pan-DEGs encoding Pam16p and Pam18p were found to be upregulated in our transcriptome analysis (Figures 2A, B). Despite the large amount of data collected so far about the roles of $\operatorname{Tim} 22$ and $\operatorname{Tim} 23$ complexes in yeast mitochondria, considerably less is known about their roles in yeast fermentation/ethanol stress. However, Short et al. (2012) showed that yeast temperature sensitive mutant strains for PAM16 have defects in fermentation linked to lipid metabolism. Moreover, an upregulated Pan-DEG in our transcriptome analysis, $M D J 2$, encode a chaperone belonging to the HSP40 family that regulates Hsp70 chaperone activity and interacts with Pam18p (Mokranjac et al., 2005). In addition, the transcriptome analysis of lager yeast cells revealed upregulation of TOM6 and TOM7 Pan-DEGs (Figures 2A, B), both encoding small protein components of the TOM complex (Dekker et al., 1998). At present, the roles of Tom6 $\mathrm{p}$ and Tom7p in yeast fermentation/ethanol stress remain unknown.

Two important Pan-DEGs found to be upregulated in our transcriptome analysis, $P H B 1$ and $P H B 2$ (Figures 2A, B), encode the proteins prohibitin 1 (Phb1p) and $2(\mathrm{Phb} 2 \mathrm{p})$, which are part of a large chaperone complex that stabilizes protein structures and is involved in the regulation of yeast replicative life span and mtUPR (Coates et al., 1997; Nijtmans, 2000). In the context of aging and replicative life span, the impact of Phb1p/2p expression during $\mathrm{VHG} / \mathrm{HG}$ beer fermentation and/or yeast reuse is unknown, despite the fact that a mixed aged yeast population is commonly observed in mostly ale/lager fermentations (Smart et al., 2000; Powell et al., 2003). Moreover, yeast $p h b 1$ and $p h b 2$ mutants are defective in mitochondrial segregation from mother cells to daughter cells, resulting in delayed segregation of mitochondria (Piper et al., 2002). Interestingly, loss of the orthologous prohibitin in Caenorhabditis elegans affected the morphology of mitochondria, resulting in fragmented and disorganized structures (Sanz et al., 2003), a phenotype previously observed in yeast strains used for sake (Kitagaki and Shimoi, 2007) and cider (Lloyd et al., 1996) after prolonged anaerobiosis under high concentration of ethanol $(>10 \% \mathrm{v} / \mathrm{v})$. In animal cells, mitochondrial fragmentation is a feature of mitochondrial proteostasis that is activated in response to a high number of misfolded proteins, but that is also observed during mitophagy and programmed cell death (Moehle et al., 2019). Similarly, Fislp, a protein involved in mitochondria and peroxisome maintenance in yeast, is upregulated when cells are subjected to high ethanol concentrations, thereby promoting mitochondrial fragmentation and inhibition of apoptosis (Kitagaki et al., 2007).

Taking into account mitochondria structure, YME1 and AFG3 were also found to be upregulated in lager yeast cells (Figures 2A, B). These Pan-DEGs encode the mitochondrial ATP-dependent metallopeptidase (AAA protease) Ymelp and Afg $3 p$, respectively, which are necessary for degradation of unfolded or misfolded proteins associated with the mitochondrial inner membrane (Arlt et al., 1996; Schreiner et al., 2012). Despite the fact that the specific roles of Ymelp and Afg $3 p$ in VHG/HG beer fermentation or yeast reuse are currently unknown, data regarding the modulation of mitochondria activity upon ethanol exposure indicates that ethanol increases oxidative stress and induces the formation of mitochondrial permeability transition (MPT). MPT is a protein structure that forms a pore across the inner and outer membranes of mitochondria, leading to the depolarization of membrane potential, uncoupling of oxidative phosphorylation and ATP depletion, rupture of the outer mitochondrial membrane, and apoptosis induction (Pastorino et al., 1999; Hoek et al., 2002). Interestingly, AAA proteases seem to be essential to coordinate many functions within mitochondria, including mitochondrial genome stability, respiratory chain complexes synthesis, and the mitochondrial membrane metabolism (Patron et al., 2018). Moreover, AAA proteases are essential to modulate the activity of the mitochondrial $\mathrm{Ca}^{2+}$ uniporter (MCU) complex. Mutations in mammalian mitochondrial AAA proteases induce constitutive MCU activity and deregulated mitochondrial $\mathrm{Ca}^{2+}$ influx, leading to cell death (König et al., 2016). This suggests that yeast AAA proteases may have essential roles in maintaining mitochondrial structure and function during beer fermentation and ethanol stress, and dysfunctions in mitochondrial AAA proteases are likely to affect brewing yeast viability and vitality. 
Besides the protein complexes linked to mitochondrial structure and function, our transcriptome analysis revealed an additional eight upregulated genes during beer fermentation (Figure 3A) that encode for mitochondrial molecular chaperones. These included three upregulated Pan-DEGs belonging to the HSP40 family (MDJ1, MDJ2, and JAC1), one to the HSP60 family (HSP60), one to the HSP70 family (ECM10), and one to the AAA+ family (HSP78) (Figures 2A, B). The interaction between mitochondrial Hsp40 and Hsp70 proteins has been extensively documented, being involved in the translocation of proteins to the matrix and folding (Liu et al., 2001). The chaperone Hsp60p is a fundamental protein required to assist the folding and import of different target proteins to the mitochondrial matrix (Reading et al., 1989), also being important for the replication of mitochondrial DNA in yeast (Kaufman et al., 2003). Finally, Hsp78p is a chaperone that displays similar functions with those of the mitochondrial Hsp70 system (Schmitt et al., 1995). Biochemical studies have indicated cooperation between the Hsp70 system and Hsp78p, forming a bichaperone Hsp70-Hsp78 system that assists in protein refolding after stress induction (Krzewska et al., 2001). Similar to Hsp60p, available evidence suggests that Hsp78p is required for the maintenance of mitochondrial genome integrity (Schmitt, 1996). Thus, it is clear that proteostasis mechanisms in mitochondria play a central role in the maintenance of both proteins and mitochondria nucleoid structure and function, the latter of which profoundly affects beer fermentation (Smart, 2007) and hybrid brewing yeast strain adaptability to temperature (Baker et al., 2019).

\section{DISCUSSION}

Different organelles such as ER, cytosol, and mitochondria display a set of molecules/proteins that are essential for proteostasis under environmental conditions that are prone to induce protein misfolding/unfolding and amorphous aggregate formation, both potentially leading to proteotoxicity. One such condition is beer fermentation, where brewing yeast strains require protection from the toxic and pleiotropic effects of ethanol. In order to deal with ethanol and maintain proteostasis during beer fermentation, the major cellular compartments (e.g. mitochondria, ER, and cytosol) must communicate with one another to mount a systemic cell response (Figure 4).

Multiple lines of evidence indicate that organellar proteostasis is a concerted process that is directly connected with different biological processes, such as metabolism and aging (Raimundo and Kriško, 2018). This so-called "inter-organellar/crossorganellar communication/response" or CORE is dependent on a series of signaling-associated and/or protein networks that include HSPs and their target molecules (Raimundo and Kriško, 2018). Interestingly, one hallmark of the CORE is the

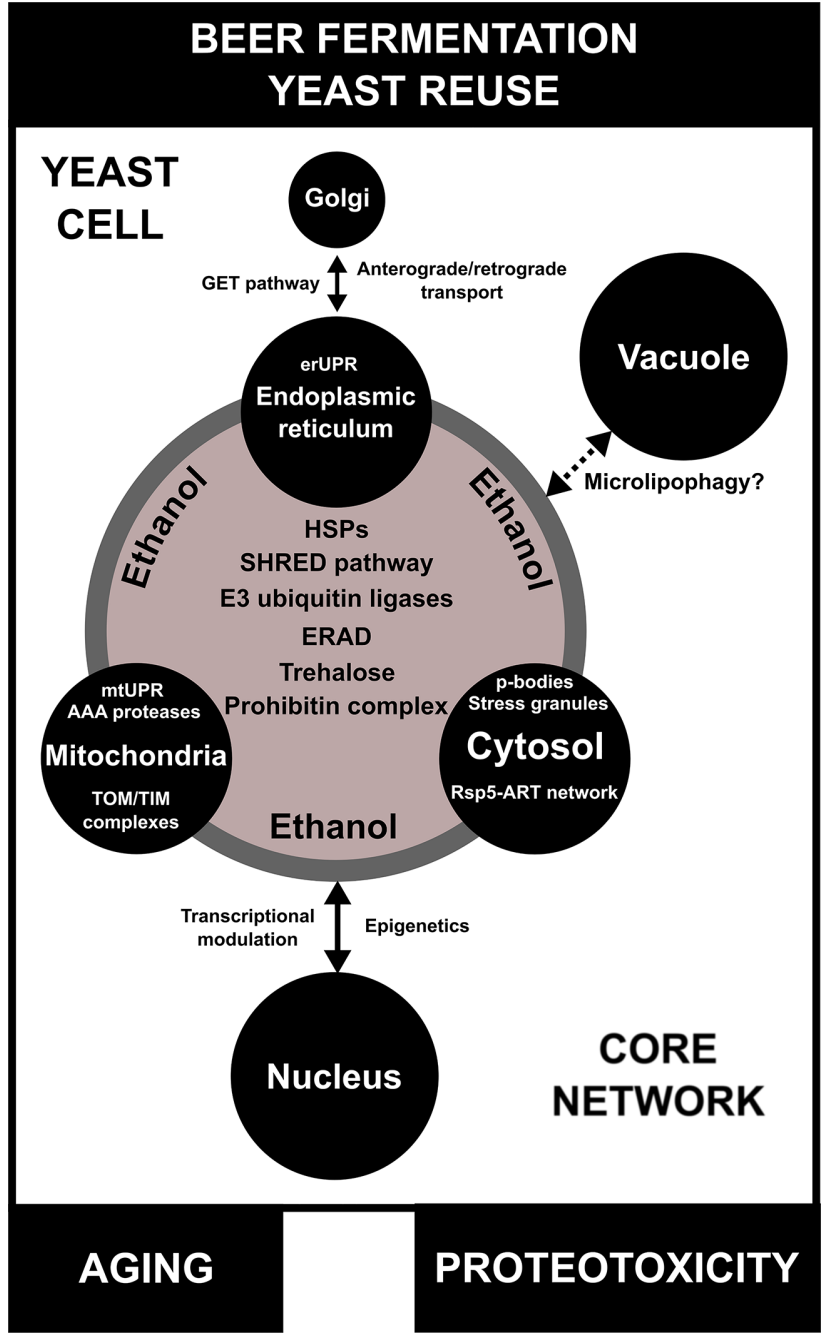

FIGURE 4 | A model for inter-organellar/cross-organellar communication/ response proteostasis (CORE network) in brewing yeast. During beer fermentation and/or yeast reuse, the endoplasmic reticulum (ER), mitochondria, and cytosol regulate proteostasis/protein quality by monitoring their environments and communicating with one another by means of the CORE network. In conditions of proteotoxicity induced by ethanol during beer fermentation, the CORE network is activated and is composed of different proteins/pathways, such as heat shock proteins (HSPs), endoplasmic reticulum-associated protein degradation (ERAD), the stress-induced, homeostatically regulated protein degradation (SHRED) pathway, E3 ubiquitin ligases, and the prohibitin complex. Trehalose, a molecular chaperone necessary for proteotoxic response, is also part of the CORE network. Additionally, each organelle has its own particular mechanisms of protein quality control/proteostasis. The impact of the CORE network in the proteostasis response of vacuoles of brewing yeast is not well understood, but may be associated with microlipophagy. Finally, proteotoxicity induced by ethanol regulates transcriptional activity and epigenetic mechanisms in the nucleus, which are influenced by CORE network components. Moreover, the CORE network activity and proteotoxicity are potentially linked to aging in brewing yeast cells. 
upregulation of multiple genes and proteins linked to proteostasis, including PDI1, HSP26, and HSP90 (Perić et al., 2016). However, we speculate that other protein and small molecule networks, such as those composed of E3 ubiquitin ligases, the SHRED pathway, trehalose biosynthesis, ERAD, and the prohibitin complex, could be essential components of a larger CORE network that is upregulated during beer fermentation (Figure 4). The activation of a CORE network may impact different aspects of fermentative metabolism that are crucial for yeast viability and/or vitality and further use in serial repitching. For example, it was observed in C. elegans that mitochondrial proteotoxicity increases fatty acid synthesis and promotes lipid accumulation, a condition associated with mitochondrial-tocytosolic stress response that is essential for C. elegans survival (Kim et al., 2016). Similarly, we observed in our transcriptome analysis an increase in the expression of genes related to lipid biosynthesis in lager yeast (Figures S11 and S12), pointing to a potentially conserved CORE network in eukaryotes. Furthermore, the roles of inter-organellar proteostasis mechanisms in the replicative and chronological life span of yeast cells have been demonstrated previously (Perić et al., 2016; Chadwick et al., 2019), which are very likely to affect brewing. Finally, a number of important questions remain about how the CORE network may modulate other organelles (e.g. nucleus and vacuole) during beer fermentation (Figure 4). As described above, some components of organellar proteostasis influence transcriptional activity in the nucleus. Recently, Andréasson et al. (2019) demonstrated an important connection between mitochondria and nucleus for proteostasis and cell metabolism. However, little is known about epigenetic modulation during proteotoxic stress induced by ethanol. In the same sense, how the CORE network connects with vacuoles is an open question (Figure 4). Noteworthy, it was demonstrated that in conditions of lipid imbalance, unfolded ER proteins can be removed by lipid droplets and targeted to the vacuole for degradation by microlipophagy (Vevea et al., 2015). However, the impact of this mechanism remains to be determined in beer fermentation.

To evaluate the importance of each component of the CORE network for beer fermentation, it is indispensable to get high quality RNA-seq data from different $S$. pastorianus strains in conditions of industrial yeast propagation and beer fermentation.

\section{REFERENCES}

Abe, F., and Horikoshi, K. (2005). Enhanced production of isoamyl alcohol and isoamyl acetate by ubiquitination-deficient Saccharomyces cerevisiae mutants. Cell. Mol. Biol. Lett. 10, 383-388.

Alexander, W. G., Peris, D., Pfannenstiel, B. T., Opulente, D. A., Kuang, M., and Hittinger, C. T. (2016). Efficient engineering of marker-free synthetic allotetraploids of Saccharomyces. Fungal Genet. Biol. FG B. 89, 10-17. doi: 10.1016/j.fgb.2015.11.002

Alexandre, H., Ansanay-Galeote, V., Dequin, S., and Blondin, B. (2001). Global gene expression during short-term ethanol stress in Saccharomyces cerevisiae. FEBS Lett. 498, 98-103. doi: 10.1016/S0014-5793(01)02503-0

Anderson, P., and Kedersha, N. (2008). Stress granules: the Tao of RNA triage. Trends Biochem. Sci. 33, 141-150. doi: 10.1016/j.tibs.2007.12.003
It can be potentially achieved by tagging the major genes of $S$. cerevisiae and $S$. eubayanus linked to the CORE network followed by interspecies hybridization to generate $S$. pastorianus strains by different techniques, like $\mathrm{HyPr}$ (Alexander et al., 2016), and testing them in brewery environment. On the other hand, the use of different proteome techniques to evaluate the contribution of CORE components is also welcome as well as the generation of $S$. pastorianus mutant strains for CORE components by uding CRISPR-Cas9 technology (de Vries et al., 2017).

In conclusion, a better understanding of the CORE network in the context of beer fermentation and/or ethanol stress will allow us to improve different aspects of brewing, from ethanol tolerance in VHG/HG fermentation to yeast reuse, potentially allowing us to select yeast strains with high tolerance to ethanol or diminished aging, which will ultimately improve beer yield and quality.

\section{DATA AVAILABILITY STATEMENT}

Publicly available datasets were analyzed in this study. These data can be found at Gene Expression Omnibus (GSE9423, GSE10205, and GSE16376).

\section{AUTHOR CONTRIBUTIONS}

DB contributed to the design, acquisition, analysis, and interpretation of data for the work. DB, BT, and MM contributed to drafting the work and prepared the final work. DB prepared the figures and all authors approved the final manuscript.

\section{SUPPLEMENTARY MATERIAL}

The Supplementary Material for this article can be found online at: https://www.frontiersin.org/articles/10.3389/fgene.2020. 00002/full\#supplementary-material

Andréasson, C., Ott, M., and Büttner, S. (2019). Mitochondria orchestrate proteostatic and metabolic stress responses. EMBO Rep. 20, e47865. doi: 10.15252/embr.201947865

Aranda, A., Querol, A., and del Olmo, M. L. (2002). Correlation between acetaldehyde and ethanol resistance and expression of HSP genes in yeast strains isolated during the biological aging of sherry wines. Arch. Microbiol. 177, 304-312. doi: 10.1007/s00203-001-0391-1

Arlt, H., Tauer, R., Feldmann, H., Neupert, W., and Langer, T. (1996). The YTA10-12 complex, an AAA protease with chaperone-like activity in the inner membrane of mitochondria. Cell 85, 875-885. doi: 10.1016/S0092-8674(00) 81271-4

Baker, E. P., Peris, D., Moriarty, R. V., Li, X. C., Fay, J. C., and Hittinger, C. T. (2019). Mitochondrial DNA and temperature tolerance in lager yeasts. Sci. Adv. 5, eaav1869. doi: 10.1126/sciadv.aav1869 
Borkovich, K. A., Farrelly, F. W., Finkelstein, D. B., Taulien, J., and Lindquist, S. (1989). Hsp82 is an essential protein that is required in higher concentrations for growth of cells at higher temperatures. Mol. Cell. Biol. 9, 3919-3930. doi: 10.1128/MCB.9.9.3919

Braakman, I., and Hebert, D. N. (2013). Protein folding in the endoplasmic reticulum. Cold Spring Harb. Perspect. Biol. 5, a013201-a013201. doi: 10.1101/ cshperspect.a013201

Brejning, J., Arneborg, N., and Jespersen, L. (2005). Identification of genes and proteins induced during the lag and early exponential phase of lager brewing yeasts. J. Appl. Microbiol. 98, 261-271. doi: 10.1111/j.1365-2672.2004.02472.x

Brodsky, J. L., and Wojcikiewicz, R. J. (2009). Substrate-specific mediators of ER associated degradation (ERAD). Curr. Opin. Cell Biol. 21, 516-521. doi: 10.1016/j.ceb.2009.04.006

Buchberger, A., Bukau, B., and Sommer, T. (2010). Protein quality control in the cytosol and the endoplasmic reticulum: brothers in arms. Mol. Cell 40, 238252. doi: 10.1016/j.molcel.2010.10.001

Cashikar, A. G., Duennwald, M., and Lindquist, S. L. (2005). A chaperone pathway in protein disaggregation: Hsp26 alters the nature of protein aggregates to facilitate reactivation by Hsp104. J. Biol. Chem. 280, 23869-23875. doi: 10.1074/jbc.M502854200

Chadwick, S. R., Fazio, E. N., Etedali-Zadeh, P., Genereaux, J., Duennwald, M. L., and Lajoie, P. (2019). A functional unfolded protein response is required for chronological aging in Saccharomyces cerevisiae. Curr. Genet. doi: 10.1007/ s00294-019-01019-0

Chapman, R. E., and Walter, P. (1997). Translational attenuation mediated by an mRNA intron. Curr. Biol. 7, 850-859. doi: 10.1016/S0960-9822(06)00373-3

Chartron, J. W., Clemons, W. M., and Suloway, C. J. (2012). The complex process of GETting tail-anchored membrane proteins to the ER. Curr. Opin. Struct. Biol. 22, 217-224. doi: 10.1016/j.sbi.2012.03.001

Clerc, S., Hirsch, C., Oggier, D. M., Deprez, P., Jakob, C., Sommer, T., et al. (2009). $\mathrm{Htm} 1$ protein generates the $\mathrm{N}$-glycan signal for glycoprotein degradation in the endoplasmic reticulum. J. Cell Biol. 184, 159-172. doi: 10.1083/jcb.200809198

Coates, P. J., Jamieson, D. J., Smart, K., Prescott, A. R., and Hall, P. A. (1997). The prohibitin family of mitochondrial proteins regulate replicative lifespan. Curr. Biol. 7, 607-610. doi: 10.1016/S0960-9822(06)00261-2

Cray, J. A., Stevenson, A., Ball, P., Bankar, S. B., Eleutherio, E. C., Ezeji, T. C., et al. (2015). Chaotropicity: a key factor in product tolerance of biofuel-producing microorganisms. Curr. Opin. Biotechnol. 33, 228-259. doi: 10.1016/ j.copbio.2015.02.010

Davis, A. J., Alder, N. N., Jensen, R. E., and Johnson, A. E. (2007). The Tim9p/10p and Tim $8 \mathrm{p} / 13 \mathrm{p}$ complexes bind to specific sites on Tim $23 \mathrm{p}$ during mitochondrial protein import. Mol. Biol. Cell 18, 475-486. doi: 10.1091/ mbc.e06-06-0546

de Vries, A. R. G., de Groot, P. A., van den Broek, M., and Daran, J.-M. G. (2017). CRISPR-Cas 9 mediated gene deletions in lager yeast. Saccharomyces pastorianus. Microb. Cell Factories 16. doi: 10.1186/s12934-017-0835-1

Dekker, P. J. T., Ryan, M. T., Brix, J., Müller, H., Hönlinger, A., and Pfanner, N. (1998). Preprotein translocase of the outer mitochondrial membrane: molecular dissection and assembly of the general import pore complex. Mol. Cell. Biol. 18, 6515-6524. doi: 10.1128/MCB.18.11.6515

Denic, V., Dotsch, V., and Sinning, I. (2013). Endoplasmic reticulum targeting and insertion of tail-anchored membrane proteins by the GET pathway. Cold Spring Harb. Perspect. Biol. 5, a013334-a013334. doi: 10.1101/ cshperspect.a013334

English, A. R., and Voeltz, G. K. (2013). Endoplasmic reticulum structure and interconnections with other organelles. Cold Spring Harb. Perspect. Biol. 5, a013227-a013227. doi: 10.1101/cshperspect.a013227

Ernandes, J. R., Williams, J. W., Russell, I., and Stewart, G. G. (1993). Respiratory deficiency in brewing yeast strains-effects on fermentation, flocculation, and beer flavor components. J. Am. Soc Brew. Chem. 51, 16-20. doi: 10.1094/ ASBCJ-51-0016

Esteban-Pretel, G., Marín, M. P., Romero, A. M., Ponsoda, X., Ballestin, R., Canales, J. J., et al. (2011). Protein traffic is an intracellular target in alcohol toxicity. Pharmaceuticals 4, 741-757. doi: 10.3390/ph4050741

Ferris, S. P., Kodali, V. K., and Kaufman, R. J. (2014). Glycoprotein folding and quality-control mechanisms in protein-folding diseases. Dis. Model. Mech. 7, 331-341. doi: 10.1242/dmm.014589
Friedmann, E., Salzberg, Y., Weinberger, A., Shaltiel, S., and Gerst, J. E. (2002). YOS9, the putative yeast homolog of a gene amplified in osteosarcomas, is involved in the endoplasmic reticulum (ER)-Golgi transport of GPI-anchored proteins. J. Biol. Chem. 277, 35274-35281. doi: 10.1074/jbc.M201044200

Gardner, R. G., Nelson, Z. W., and Gottschling, D. E. (2005). Degradationmediated protein quality control in the nucleus. Cell 120, 803-815. doi: 10.1016/j.cell.2005.01.016

Gebert, N., Gebert, M., Oeljeklaus, S., von der Malsburg, K., Stroud, D. A., Kulawiak, B., et al. (2011). Dual function of Sdh3 in the respiratory chain and TIM22 protein translocase of the mitochondrial inner membrane. Mol. Cell 44, 811-818. doi: 10.1016/j.molcel.2011.09.025

Ghosh, P., Liu, Q.-H., and Lakshman, M. R. (1995). Long-term ethanol exposure impairs glycosylation of both $\mathrm{N}$ - and O-glycosylated proteins in rat liver. Metabolism 44, 890-898. doi: 10.1016/0026-0495(95)90242-2

Gibson, B. R., Lawrence, S. J., Leclaire, J. P. R., Powell, C. D., and Smart, K. A. (2007). Yeast responses to stresses associated with industrial brewery handling. FEMS Microbiol. Rev. 31, 535-569. doi: 10.1111/j.1574-6976.2007.00076.x

Gibson, B. R., Lawrence, S. J., Boulton, C. A., Box, W. G., Graham, N. S., Linforth, R. S. T., et al. (2008). The oxidative stress response of a lager brewing yeast strain during industrial propagation and fermentation: oxidative stress response of lager brewing yeast. FEMS Yeast Res. 8, 574-585. doi: 10.1111/ j.1567-1364.2008.00371.x

Gilbert, H. F. (1997). Protein disulfide isomerase and assisted protein folding. J. Biol. Chem. 272, 29399-29402. doi: 10.1074/jbc.272.47.29399

Goder, V., and Melero, A. (2011). Protein O-mannosyltransferases participate in ER protein quality control. J. Cell Sci. 124, 144-153. doi: 10.1242/jcs.072181

Gong, Y., Kakihara, Y., Krogan, N., Greenblatt, J., Emili, A., Zhang, Z., et al. (2009). An atlas of chaperone-protein interactions in Saccharomyces cerevisiae: implications to protein folding pathways in the cell. Mol. Syst. Biol. 5, 275. doi: 10.1038/msb.2009.26

Gorter de Vries, A. R., Voskamp, M. A., van Aalst, A. C. A., Kristensen, L. H., Jansen, L., van den Broek, M., et al. (2019a). Laboratory evolution of a Saccharomyces cerevisiae $\times S$. eubayanus hybrid under simulated lagerbrewing conditions. Front. Genet. 10. 1-18. doi: 10.3389/fgene.2019.00242

Gorter de Vries, A. R., Pronk, J. T., and Daran, J.-M. G. (2019b). Lager-brewing yeasts in the era of modern genetics. FEMS Yeast Res. 19 1-17. doi: 10.1093/ femsyr/foz063

Hallsworth, J. E. (1998). Ethanol-induced water stress in yeast. J. Ferment. Bioeng. 85, 125-137. doi: 10.1016/S0922-338X(97)86756-6

Harding, H. P., Zhang, Y., Bertolotti, A., Zeng, H., and Ron, D. (2000). Perk is essential for translational regulation and cell survival during the unfolded protein response. Mol. Cell 5, 897-904. doi: 10.1016/S1097-2765(00)80330-5

Haslbeck, M., Braun, N., Stromer, T., Richter, B., Model, N., Weinkauf, S., et al. (2004). Hsp42 is the general small heat shock protein in the cytosol of Saccharomyces cerevisiae. EMBO J. 23, 638-649. doi: 10.1038/sj.emboj.7600080

Hetz, C., Chevet, E., and Oakes, S. A. (2015). Proteostasis control by the unfolded protein response. Nat. Cell Biol. 17, 829-838. doi: 10.1038/ncb3184

Hiraishi, H., Mochizuki, M., and Takagi, H. (2006). Enhancement of stress tolerance in Saccharomyces cerevisiae by overexpression of ubiquitin ligase Rsp5 and ubiquitin-conjugating enzymes. Biosci. Biotechnol. Biochem. 70, 2762-2765. doi: 10.1271/bbb.60250

Hoek, J. B., Cahill, A., and Pastorino, J. G. (2002). Alcohol and mitochondria: a dysfunctional relationship. Gastroenterology 122, 2049-2063. doi: 10.1053/ gast.2002.33613

Horinouchi, T., Yoshikawa, K., Kawaide, R., Furusawa, C., Nakao, Y., Hirasawa, T., et al. (2010). Genome-wide expression analysis of Saccharomyces pastorianus orthologous genes using oligonucleotide microarrays. J. Biosci. Bioeng. 110, 602-607. doi: 10.1016/j.jbiosc.2010.05.011

Huuskonen, A., Markkula, T., Vidgren, V., Lima, L., Mulder, L., Geurts, W., et al. (2010). Selection from industrial lager yeast strains of variants with improved fermentation performance in very-high-gravity worts. Appl. Environ. Microbiol. 76, 1563-1573. doi: 10.1128/AEM.03153-09

Iwahashi, H., Nwaka, S., Obuchi, K., and Komatsu, Y. (1998). Evidence for the interplay between trehalose metabolism and Hsp104 in yeast. Appl. Environ. Microbiol. 64, 4614-4617. doi: 10.1128/AEM.64.11.4614-4617.1998

König, T., Tröder, S. E., Bakka, K., Korwitz, A., Richter-Dennerlein, R., Lampe, P. A., et al. (2016). The m-AAA protease associated with neurodegeneration 
limits MCU activity in mitochondria. Mol. Cell 64, 148-162. doi: 10.1016/ j.molcel.2016.08.020

Kamena, F., Diefenbacher, M., Kilchert, C., Schwarz, H., and Spang, A. (2008). Yptlp is essential for retrograde Golgi-ER transport and for Golgi maintenance in. S. cerevisiae. J. Cell Sci. 121, 1293-1302. doi: 10.1242/jcs.016998

Kato, K., Yamamoto, Y., and Izawa, S. (2011). Severe ethanol stress induces assembly of stress granules in. Saccharomyces cerevisiae. Yeast 28, 339-347. doi: 10.1002/yea. 1842

Kaufman, B. A., Kolesar, J. E., Perlman, P. S., and Butow, R. A. (2003). A function for the mitochondrial chaperonin Hsp60 in the structure and transmission of mitochondrial DNA nucleoids in Saccharomyces cerevisiae. J. Cell Biol. 163, 457-461. doi: 10.1083/jcb.200306132

Kettern, N., Dreiseidler, M., Tawo, R., and Höhfeld, J. (2010). Chaperone-assisted degradation: multiple paths to destruction. Biol. Chem. 391, 481-489. doi: 10.1515/bc.2010.058

Kim, Y. E., Hipp, M. S., Bracher, A., Hayer-Hartl, M., and Ulrich Hartl, F. (2013). Molecular chaperone functions in protein folding and proteostasis. Annu. Rev. Biochem. 82, 323-355. doi: 10.1146/annurev-biochem-060208-092442

Kim, H.-E., Grant, A. R., Simic, M. S., Kohnz, R. A., Nomura, D. K., Durieux, J., et al. (2016). Lipid biosynthesis coordinates a mitochondrial-to-cytosolic stress response. Cell 166, 1539-1552.e16. doi: 10.1016/j.cell.2016.08.027

Kitagaki, H., and Shimoi, H. (2007). Mitochondrial dynamics of yeast during sake brewing. J. Biosci. Bioeng. 104, 227-230. doi: 10.1263/jbb.104.227

Kitagaki, H., and Takagi, H. (2014). Mitochondrial metabolism and stress response of yeast: applications in fermentation technologies. J. Biosci. Bioeng. 117, 383-393. doi: 10.1016/j.jbiosc.2013.09.011

Kitagaki, H., Araki, Y., Funato, K., and Shimoi, H. (2007). Ethanol-induced death in yeast exhibits features of apoptosis mediated by mitochondrial fission pathway. FEBS Lett. 581, 2935-2942. doi: 10.1016/j.febslet.2007.05.048

Krzewska, J., Langer, T., and Liberek, K. (2001). Mitochondrial Hsp78, a member of the Clp/Hsp100 family in Saccharomyces cerevisiae, cooperates with Hsp70 in protein refolding. FEBS Lett. 489, 92-96. doi: 10.1016/S0014-5793(00) 02423-6

Lawrence, S. J., Wimalasena, T. T., Nicholls, S. M., Box, W. G., Boulton, C., and Smart, K. A. (2012). Incidence and characterization of petites isolated from lager brewing yeast Saccharomyces cerevisiae populations. J. Am. Soc Brew. Chem. 70, 268-274. doi: 10.1094/ASBCJ-2012-0917-01

Lee, S., Carlson, T., Christian, N., Lea, K., Kedzie, J., Reilly, J. P., et al. (2000). The Yeast heat shock transcription factor changes conformation in response to superoxide and temperature. Mol. Biol. Cell 11, 1753-1764. doi: 10.1091/ mbc.11.5.1753

Lee, M. C. S., Miller, E. A., Goldberg, J., Orci, L., and Schekman, R. (2004). Bidirectional protein transport between the ER and Golgi. Annu. Rev. Cell Dev. Biol. 20, 87-123. doi: 10.1146/annurev.cellbio.20.010403.105307

Li, B.-Z., Cheng, J.-S., Qiao, B., and Yuan, Y.-J. (2010). Genome-wide transcriptional analysis of Saccharomyces cerevisiae during industrial bioethanol fermentation. J. Ind. Microbiol. Biotechnol. 37, 43-55. doi: 10.1007/s10295-009-0646-4

Liu, Y., and Chang, A. (2008). Heat shock response relieves ER stress. EMBO J. 27, 1049-1059. doi: 10.1038/emboj.2008.42

Liu, Q., Krzewska, J., Liberek, K., and Craig, E. A. (2001). Mitochondrial Hsp70 Ssc1: role in protein folding. J. Biol. Chem. 276, 6112-6118. doi: 10.1074/ jbc.M009519200

Lloyd, D., Moran, C. A., Suller, M. T. E., Dinsdale, M. G., and Hayes, A. J. (1996). Flow cytometric monitoring of rhodamine 123 and a cyanine dye uptake by yeast during cider fermentation. J. Inst. Brew. 102, 251-259. doi: 10.1002/ j.2050-0416.1996.tb00910.x

Ma, M., and Liu, Z. L. (2012). "Molecular mechanisms of ethanol tolerance in Saccharomyces cerevisiae,", in Microbial Stress Tolerance for Biofuels. Ed. Z. L. Liu (Berlin, Heidelberg: Springer Berlin Heidelberg), 77-115. doi: 10.1007/9783-642-21467-7_4

Mager, W. H., and Ferreira, P. M. (1993). Stress response of yeast. Biochem. J. 290, 1-13. doi: 10.1042/bj2900001

Mayr, C., Richter, K., Lilie, H., and Buchner, J. (2000). Cpr6 and Cpr7, two closely related Hsp90-associated immunophilins from Saccharomyces cerevisiae, differ in their functional properties. J. Biol. Chem. 275, 34140-34146. doi: 10.1074/ jbc.M005251200
Miyagawa, K.-I., Ishiwata-Kimata, Y., Kohno, K., and Kimata, Y. (2014). Ethanol stress impairs protein folding in the endoplasmic reticulum and activates Ire1 in Saccharomyces cerevisiae. Biosci. Biotechnol. Biochem. 78, 1389-1391. doi: 10.1080/09168451.2014.921561

Mizunaga, T., Katakura, Y., Miura, T., and Maruyama, Y. (1990). Purification and characterization of yeast protein disulfide isomerase. J. Biochem. (Tokyo) 108, 846-851. doi: 10.1093/oxfordjournals.jbchem.a123291

Moehle, E. A., Shen, K., and Dillin, A. (2019). Mitochondrial proteostasis in the context of cellular and organismal health and aging. J. Biol. Chem. 294, 53965407. doi: 10.1074/jbc.TM117.000893

Mokranjac, D., and Neupert, W. (2009). Thirty years of protein translocation into mitochondria: unexpectedly complex and still puzzling. Biochim. Biophys. Acta BBA Mol. Cell Res. 1793, 33-41. doi: 10.1016/j.bbamcr.2008.06.021

Mokranjac, D., Sichting, M., Popov-Čeleketič, D., Berg, A., Hell, K., and Neupert, W. (2005). The import motor of the yeast mitochondrial TIM23 preprotein translocase contains two different J proteins, Tim14 and Mdj2. J. Biol. Chem. 280, 31608-31614. doi: 10.1074/jbc.M502397200

Molinari, M. (2007). N-glycan structure dictates extension of protein folding or onset of disposal. Nat. Chem. Biol. 3, 313-320. doi: 10.1038/nchembio880

Mori, K. (2015). The unfolded protein response: the dawn of a new field. Proc. Jpn. Acad. Ser. B. 91, 469-480. doi: 10.2183/pjab.91.469

Nathan, D. F., Vos, M. H., and Lindquist, S. (1997). In vivo functions of the Saccharomyces cerevisiae Hsp90 chaperone. Proc. Natl. Acad. Sci. 94, 1294912956. doi: 10.1073/pnas.94.24.12949

Navarro-Tapia, E., Nana, R. K., Querol, A., and Pérez-Torrado, R. (2016). Ethanol cellular defense induce unfolded protein response in yeast. Front. Microbiol. 7, 1-12. doi: 10.3389/fmicb.2016.00189

Navarro-Tapia, E., Pérez-Torrado, R., and Querol, A. (2017). Ethanol effects involve non-canonical unfolded protein response activation in yeast cells. Front. Microbiol. 8. doi: 10.3389/fmicb.2017.00383

Neupert, W., and Herrmann, J. M. (2007). Translocation of Proteins into Mitochondria. Annu. Rev. Biochem. 76, 723-749. doi: 10.1146/ annurev.biochem.76.052705.163409

Nijtmans, L. G. J. (2000). Prohibitins act as a membrane-bound chaperone for the stabilization of mitochondrial proteins. EMBO J. 19, 2444-2451. doi: 10.1093/ emboj/19.11.2444

Nillegoda, N. B., Theodoraki, M. A., Mandal, A. K., Mayo, K. J., Ren, H. Y., Sultana, R., et al. (2010). Ubr1 and Ubr2 function in a quality control pathway for degradation of unfolded cytosolic proteins. Mol. Biol. Cell 21, 2102-2116. doi: 10.1091/mbc.e10-02-0098

O'Connor-Cox, E. S. C., Lodolo, E. J., and Axcell, B. C. (1996). Mitochondrial relevance to yeast fermentative performance: a review. J. Inst. Brew. 102, 19-25. doi: 10.1002/j.2050-0416.1996.tb00890.x

Odumeru, J. A., D’Amore, T., Russell, I., and Stewart, G. G. (1992). Effects of heat shock and ethanol stress on the viability of aSaccharomyces uvarum (carlsbergensis) brewing yeast strain during fermentation of high gravity wort. J. Ind. Microbiol. 10, 111-116. doi: 10.1007/BF01583843

Okuno, M., Kajitani, R., Ryusui, R., Morimoto, H., Kodama, Y., and Itoh, Y. T. (2016). Next-generation sequencing analysis of lager brewing yeast strains reveals the evolutionary history of interspecies hybridization. DNA Res. 23, 6782. doi: $10.1093 /$ dnares/dsv037

Panaretou, B., Siligardi, G., Meyer, P., Maloney, A., Sullivan, J. K., Singh, S., et al. (2002). Activation of the ATPase activity of Hsp90 by the stress-regulated cochaperone Aha1. Mol. Cell 10, 1307-1318. doi: 10.1016/S1097-2765(02) 00785-2

Parsell, D. A., Taulien, J., Lindquist, S. L., Viitanen, P., Jaenicke, R., Horwich, A., et al. (1993). The role of heat-shock proteins in thermotolerance. Philos. Trans. R. Soc Lond. B. Biol. Sci. 339, 279-286. doi: 10.1098/rstb.1993.0026

Pastorino, J. G., Marcineviciute, A., Cahill, A., and Hoek, J. B. (1999). Potentiation by chronic ethanol treatment of the mitochondrial permeability transition. Biochem. Biophys. Res. Commun. 265, 405-409. doi: 10.1006/bbrc.1999.1696

Patron, M., Sprenger, H.-G., and Langer, T. (2018). m-AAA proteases, mitochondrial calcium homeostasis and neurodegeneration. Cell Res. 28, 296-306. doi: 10.1038/cr.2018.17

Perić, M., Dib, P. B., Dennerlein, S., Musa, M., Rudan, M., Lovrić, A., et al. (2016). Crosstalk between cellular compartments protects against proteotoxicity and extends lifespan. Sci. Rep. 6, 28751. doi: 10.1038/srep28751 
Pfeiffer, A., Stephanowitz, H., Krause, E., Volkwein, C., Hirsch, C., Jarosch, E., et al. (2016). A Complex of Html and the oxidoreductase Pdil accelerates degradation of misfolded glycoproteins. J. Biol. Chem. 291, 12195-12207. doi: 10.1074/jbc.M115.703256

Piper, P. W., Talreja, K., Panaretou, B., Moradas-Ferreira, P., Byrne, K., Praekelt, U. M., et al. (1994). Induction of major heat-shock proteins of Saccharomyces cerevisiae, including plasma membrane $\mathrm{Hsp} 30$, by ethanol levels above a critical threshold. Microbiology 140, 3031-3038. doi: 10.1099/13500872-14011-3031

Piper, P. W., Jones, G. W., Bringloe, D., Harris, N., MacLean, M., and Mollapour, M. (2002). The shortened replicative life span of prohibitin mutants of yeast appears to be due to defective mitochondrial segregation in old mother cells: prohibitin influence on yeast aging, p. w. piper et al. Aging Cell 1, 149-157. doi: 10.1046/j.1474-9728.2002.00018.x

Piper, P. W. (1995). The heat shock and ethanol stress responses of yeast exhibit extensive similarity and functional overlap. FEMS Microbiol. Lett. 134, 121127. doi: 10.1111/j.1574-6968.1995.tb07925.x

Powell, C., Quain, D., and Smart, K. (2003). The impact of brewing yeast cell age on fermentation performance, attenuation and flocculation. FEMS Yeast Res. 3, 149-157. doi: 10.1016/S1567-1356(03)00002-3

Prasad, R., Xu, C., and Ng, D. T. W. (2018). Hsp40/70/110 chaperones adapt nuclear protein quality control to serve cytosolic clients. J. Cell Biol. 217, 20192032. doi: $10.1083 /$ jcb. 201706091

Puligundla, P., Smogrovicova, D., Obulam, V. S. R., and Ko, S. (2011). Very high gravity (VHG) ethanolic brewing and fermentation: a research update. J. Ind. Microbiol. Biotechnol. 38, 1133-1144. doi: 10.1007/s10295-011-0999-3

Qing, Z., Hai, Z., Guohua, Z., Kaize, H., Zhirong, Y., and Yanling, J. (2012). Transcriptome analysis of Saccharomyces cerevisiae at the late stage of very high gravity (VHG) fermentation. Afr. J. Biotechnol. 11, 9641-9648. doi: $10.5897 / \mathrm{AJB} 12.268$

Raimundo, N., and Kriško, A. (2018). Cross-organelle communication at the core of longevity. Aging 10, 15-16. doi: 10.18632/aging.101373

Rautio, J. J., Huuskonen, A., Vuokko, H., Vidgren, V., and Londesborough, J. (2007). Monitoring yeast physiology during very high gravity wort fermentations by frequent analysis of gene expression. Yeast 24, 741-760. doi: $10.1002 /$ yea. 1510

Reading, D. S., Hallberg, R. L., and Myers, A. M. (1989). Characterization of the yeast HSP60 gene coding for a mitochondrial assembly factor. Nature 337, 655-659. doi: 10.1038/337655a0

Richter, K., Muschler, P., Hainzl, O., and Buchner, J. (2001). Coordinated ATP hydrolysis by the Hsp90 dimer. J. Biol. Chem. 276, 33689-33696. doi: 10.1074/ jbc.M103832200

Ron, D. (2002). Translational control in the endoplasmic reticulum stress response. J. Clin. Invest. 110, 1383-1388. doi: 10.1172/JCI0216784

Ruggiano, A., Foresti, O., and Carvalho, P. (2014). ER-associated degradation: protein quality control and beyond. J. Cell Biol. 204, 869-879. doi: 10.1083/ jcb.201312042

Sanz, M. A., Tsang, W. Y., Willems, E. M., Grivell, L. A., Lemire, B. D., van der Spek, H., et al. (2003). The mitochondrial prohibitin complex is essential for embryonic viability and germline function in Caenorhabditis elegans. J. Biol. Chem. 278, 32091-32099. doi: 10.1074/jbc.M304877200

Sardi, M., Krause, M., Heilberger, J., and Gasch, A. P. (2018). Genotype-byenvironment-by-environment interactions in the Saccharomyces cerevisiae transcriptomic response to alcohols and anaerobiosis. G3. GenesGenomesGenetics 8, 3881-3890. doi: 10.1534/g3.118.200677

Schmitt, M., Neupert, W., and Langer, T. (1995). Hsp78, a Clp homologue within mitochondria, can substitute for chaperone functions of mt-hsp70. EMBO J. 14, 3434-3444. doi: 10.1002/j.1460-2075.1995.tb07349.x

Schmitt, M. (1996). The molecular chaperone Hsp78 confers compartmentspecific thermotolerance to mitochondria. J. Cell Biol. 134, 1375-1386. doi: 10.1083/jcb.134.6.1375

Schreiner, B., Westerburg, H., Forné, I., Imhof, A., Neupert, W., and Mokranjac, D. (2012). Role of the AAA protease Ymel in folding of proteins in the intermembrane space of mitochondria. Mol. Biol. Cell 23, 4335-4346. doi: 10.1091/mbc.e12-05-0420

Schuldiner, M., Collins, S. R., Thompson, N. J., Denic, V., Bhamidipati, A., Punna, T., et al. (2005). Exploration of the function and organization of the yeast early secretory pathway through an epistatic miniarray profile. Cell 123, 507-519. doi: 10.1016/j.cell.2005.08.031

Semenza, J. C., Hardwick, K. G., Dean, N., and Pelham, H. R. B. (1990). ERD2, a yeast gene required for the receptor-mediated retrieval of luminal ER proteins from the secretory pathway. Cell 61, 1349-1357. doi: 10.1016/0092-8674(90) 90698-E

Sethi, R., Iyer, S. S., Das, E., and Roy, I. (2018). Discrete roles of trehalose and Hsp104 in inhibition of protein aggregation in yeast cells. FEMS Yeast Res. 18, 1-11. doi: 10.1093/femsyr/foy058

Shahsavarani, H., Sugiyama, M., Kaneko, Y., Chuenchit, B., and Harashima, S. (2012). Superior thermotolerance of Saccharomyces cerevisiae for efficient bioethanol fermentation can be achieved by overexpression of RSP5 ubiquitin ligase. Biotechnol. Adv. 30, 1289-1300. doi: 10.1016/ j.biotechadv.2011.09.002

Sharma, V. M. (2001). Quantitative target display: a method to screen yeast mutants conferring quantitative phenotypes by mutant DNA fingerprints. Nucleic Acids Res. 29, 86e-886. doi: 10.1093/nar/29.17.e86

Short, M. K., Hallett, J. P., Tar, K., Dange, T., Schmidt, M., Moir, R., et al. (2012). The yeast magmas ortholog Pam16 has an essential function in fermentative growth that involves sphingolipid metabolism. PloS One 7, e39428. doi: 10.1371/journal.pone.0039428

Sidrauski, C., and Walter, P. (1997). The transmembrane kinase Irelp is a sitespecific endonuclease that initiates mRNA splicing in the unfolded protein response. Cell 90, 1031-1039. doi: 10.1016/S0092-8674(00)80369-4

Silva, D., Brányik, T., Dragone, G., Vicente, A., Teixeira, J., and Almeida e Silva, J. (2008). High gravity batch and continuous processes for beer production: evaluation of fermentation performance and beer quality. Chem. Pap. 62, 3441. doi: 10.2478/s11696-007-0076-6

Silverstein, R. A., and Ekwall, K. (2005). Sin3: a flexible regulator of global gene expression and genome stability. Curr. Genet. 47, 1-17. doi: 10.1007/s00294004-0541-5

Singer, M. A., and Lindquist, S. (1998). Multiple effects of trehalose on protein folding in vitro and. In vivo. Mol. Cell 1, 639-648. doi: 10.1016/S1097-2765(00) 80064-7

Smart, K. A., Quain, D. E., Powell, C. D., and Van Zandycke, S. M. (2000). Replicative ageing and senescence in Saccharomyces cerevisiae and the impact on brewing fermentations. Microbiology 146, 1023-1034. doi: 10.1099/ 00221287-146-5-1023

Smart, K. A. (2007). Brewing yeast genomes and genome-wide expression and proteome profiling during fermentation. Yeast 24, 993-1013. doi: 10.1002/yea.1553

Stanley, D., Bandara, A., Fraser, S., Chambers, P. J., and Stanley, G. A. (2010). The ethanol stress response and ethanol tolerance of Saccharomyces cerevisiae. J. Appl. Microbiol. 109, 13-24. doi: 10.1111/j.1365-2672.2009.04657.x

Stefanovic, S., and Hegde, R. S. (2007). Identification of a targeting factor for posttranslational membrane protein insertion into the ER. Cell 128, 11471159. doi: $10.1016 /$ j.cell.2007.01.036

Stewart, G. G. (2010). High-gravity brewing and distilling-past experiences and future prospects. J. Am. Soc Brew. Chem. 68, 1-9. doi: 10.1094/ASBCJ-2009-1214-01

Stolz, A., Besser, S., Hottmann, H., and Wolf, D. H. (2013). Previously unknown role for the ubiquitin ligase Ubr1 in endoplasmic reticulum-associated protein degradation. Proc. Natl. Acad. Sci. 110, 15271-15276. doi: 10.1073/ pnas. 1304928110

Szathmary, R., Bielmann, R., Nita-Lazar, M., Burda, P., and Jakob, C. A. (2005). Yos9 protein is essential for degradation of misfolded glycoproteins and may function as lectin in ERAD. Mol. Cell 19, 765-775. doi: 10.1016/ j.molcel.2005.08.015

Szoradi, T., Schaeff, K., Garcia-Rivera, E. M., Itzhak, D. N., Schmidt, R. M., Bircham, P. W., et al. (2018). SHRED is a regulatory cascade that reprograms Ubr1 substrate specificity for enhanced protein quality control during stress. Mol. Cell 70, 1025-1037.e5. doi: 10.1016/j.molcel.2018.04.027

Takemori, Y., Sakaguchi, A., Matsuda, S., Mizukami, Y., and Sakurai, H. (2006). Stress-induced transcription of the endoplasmic reticulum oxidoreductin gene ERO1 in the yeast Saccharomyces cerevisiae. Mol. Genet. Genomics 275, 89-96. doi: 10.1007/s00438-005-0065-9

Thibault, G., and Ng, D. T. W. (2012). The endoplasmic reticulum-associated degradation pathways of budding yeast. Cold Spring Harb. Perspect. Biol. 4, a013193-a013193. doi: 10.1101/cshperspect.a013193 
Tomás, M., Marín, M. P., Martínez-Alonso, E., Esteban-Pretel, G., Díaz-Ruiz, A., Vázquez-Martínez, R., et al. (2012). Alcohol induces Golgi fragmentation in differentiated PC12 cells by deregulating Rab1-dependent ER-to-Golgi transport. Histochem. Cell Biol. 138, 489-501. doi: 10.1007/s00418-012-0970-z

Tsvetanova, N. G., Riordan, D. P., and Brown, P. O. (2012). The yeast Rab GTPase Ypt1 modulates unfolded protein response dynamics by regulating the stability of HAC1 RNA. PloS Genet. 8, e1002862. doi: 10.1371/journal.pgen.1002862

van Meer, G., Voelker, D. R., and Feigenson, G. W. (2008). Membrane lipids: where they are and how they behave. Nat. Rev. Mol. Cell Biol. 9, 112-124. doi: $10.1038 / \mathrm{nrm} 2330$

Verghese, J., Abrams, J., Wang, Y., and Morano, K. A. (2012). Biology of the heat shock response and protein chaperones: budding yeast (Saccharomyces cerevisiae) as a model system. Microbiol. Mol. Biol. Rev. 76, 115-158. doi: 10.1128/MMBR.05018-11

Vevea, J. D., Garcia, E. J., Chan, R. B., Zhou, B., Schultz, M., Di Paolo, G., et al. (2015). Role for lipid droplet biogenesis and microlipophagy in adaptation to lipid imbalance in yeast. Dev. Cell 35, 584-599. doi: 10.1016/ j.devcel.2015.11.010

Wang, F., Chan, C., Weir, N. R., and Denic, V. (2014). The Get1/2 transmembrane complex is an endoplasmic-reticulum membrane protein insertase. Nature 512, 441-444. doi: 10.1038/nature13471

Weibezahn, J., Schlieker, C., Tessarz, P., Mogk, A., and Bukau, B. (2005). Novel insights into the mechanism of chaperone-assisted protein disaggregation. Biol. Chem. 386., 739-744. doi: 10.1515/BC.2005.086

Weindling, E., and Bar-Nun, S. (2015). Sir2 links the unfolded protein response and the heat shock response in a stress response network. Biochem. Biophys. Res. Commun. 457, 473-478. doi: 10.1016/j.bbrc.2015.01.021

Weissman, J. S., and Kimt, P. S. (1993). Efficient catalysis of disulphide bond rearrangements by protein disulphide isomerase. Nature $365,185-188$. doi: $10.1038 / 365185 \mathrm{a} 0$

Welihinda, A. A., Tirasophon, W., Green, S. R., and Kaufman, R. J. (1998). Protein serine/threonine phosphatase Ptc2p negatively regulates the unfolded-protein response by dephosphorylating Irelp kinase. Mol. Cell. Biol. 18, 1967-1977. doi: 10.1128/MCB.18.4.1967

Welti, M., and Hülsmeier, A. J. (2014). Ethanol-induced impairment in the biosynthesis of $\mathrm{n}$-linked glycosylation: ethanol interference with $\mathrm{N}$-linked glycosylation. J. Cell. Biochem. 115, 754-762. doi: 10.1002/jcb.24713

Yamamoto, A., Mizukami, Y., and Sakurai, H. (2005). Identification of a novel class of target genes and a novel type of binding sequence of heat shock transcription factor in Saccharomyces cerevisiae. J. Biol. Chem. 280, 1191111919. doi: 10.1074/jbc.M411256200

Zhao, Y., MacGurn, J. A., Liu, M., and Emr, S. (2013). The ART-Rsp5 ubiquitin ligase network comprises a plasma membrane quality control system that protects yeast cells from proteotoxic stress. eLife 2, e00459. doi: 10.7554/ eLife.00459

Zhao, Q. (2002). A mitochondrial specific stress response in mammalian cells. EMBO J. 21, 4411-4419. doi: 10.1093/emboj/cdf445

Zolkiewski, M., Zhang, T., and Nagy, M. (2012). Aggregate reactivation mediated by the Hsp100 chaperones. Arch. Biochem. Biophys. 520, 1-6. doi: 10.1016/ j.abb.2012.01.012

Zuehlke, A. D., and Johnson, J. L. (2012). Chaperoning the chaperone: a role for the co-chaperone cpr7 in modulating Hsp90 function in Saccharomyces cerevisiae. Genetics 191, 805-814. doi: 10.1534/genetics.112.140319

Conflict of Interest: The authors declare that this work was conducted in the absence of any commercial or financial relationships that could be construed as a potential conflict of interest.

Copyright (C) 2020 Telini, Menoncin and Bonatto. This is an open-access article distributed under the terms of the Creative Commons Attribution License (CC BY). The use, distribution or reproduction in other forums is permitted, provided the original author(s) and the copyright owner(s) are credited and that the original publication in this journal is cited, in accordance with accepted academic practice. No use, distribution or reproduction is permitted which does not comply with these terms. 